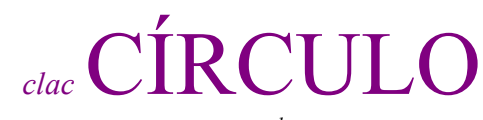

de

lingüistica

aplicada a la

ción

$49 / 2012$

\title{
SUBJETIVIDAD, ARGUMENTACIÓN Y (DES)CORTESÍA
}

\author{
Catalina Fuentes Rodríguez \\ Universidad de Sevilla
}

cfuentes en us.es

\section{Resumen}

La expresión de la subjetividad es utilizada en la argumentación y en la modulación cortés o descortés de un mensaje. El hablante recurre a ella: a) como mecanismo de refuerzo o atenuación de la (des)cortesía, b) como argumento falaz (argumentum ad hominem, ad baculum, ad misericordiam), c) como medio de asegurar la afiliación con el interlocutor. Se utiliza, pues, como calificador en la argumentación, o como un tipo de argumentos que se mueve en el plano de los sentimientos para conseguir un mayor efecto en el receptor. Puede emplearlo el hablante para acercarse cortésmente al interlocutor, o para rechazarlo de forma tajante. En este último caso el discurso es descortés y la argumentación falaz. Pero, en contra de lo esperado, es altamente rentable. Por ello es empleada en diferentes formatos textuales. En este trabajo nos acercamos a dos tipos discursivos altamente persuasivos, el político y el publicitario, que en su búsqueda de la eficacia comunicativa, acuden de forma recurrente a la emoción como estrategia. El marco metodológico en el que nos movemos es el de una pragmalingüística integral donde convergen la teoría de la enunciación, la teoría de la argumentación y la cortesía verbal.

Palabras clave: subjetividad, pragmática, argumentación, (des)cortesía

Fuentes Rodríguez, Catalina. 2012.

Subjetividad, argumentación y (des)cortesía

Círculo de Lingüística Aplicada a la Comunicación 49, 49-92.

http://www.ucm.es/info/circulo/no49/fabregas.pdf

DOI: http://dx.doi.org/10.5209/rev_CLAC.2012.v49.40615

\section{(C) 2012 Catalina Fuentes Rodríguez}

Círculo de Lingüística Aplicada a la Comunicación (clac)

Universidad Complutense de Madrid. ISSN 1576-4737. http://www.ucm.es/info/circulo 


\begin{abstract}
Subjectivity, argumentation and (im)politeness

Subjectivity is used in argumentation and (im)politeness. It is very effective in the persuasion: a) as a mechanism of reinforcement or attenuation of the (im)politeness, b) as a fallacious argument (argumentum ad hominem, ad baculum, ad misericordiam), c) as a means of ensuring the affiliation with the partner. It is used, therefore, as a qualifier of the argument, or as a kind of arguments that use emotions to achieve a greater effect on the receiver. The speaker does it in order to be polite with his interlocutor, or to reject it in a blunt way. In the latter case the discourse is impolite and the argument, a fallacy. But, contrary to expectations, it is highly profitable in different textual formats. In this work we analyse two highly persuasive discursive types, politics or advertising, attending recurrently the emotion as a strategy in their search for efficient communication. The methodological framework in which we operate is a comprehensive pragmalinguistics where converge enunciation theory, theory of argumentation or verbal politeness.
\end{abstract}

Key words: subjectivity, pragmatics, argumentation, (im)politeness

Índice

\title{
Resumen 49
}

\section{Introducción 51}

2. Marco teórico y metodología de análisis: El concepto de subjetividad y su inscripción en la teoría lingüística 52

\subsection{La modalidad lingüística 54}

\subsection{Emoción, argumentación y cortesía 59}

\section{La subjetividad en el discurso político 64}

4. Emoción para la persuasión: el texto publicitario 71

\section{Conclusiones 79}

\section{Bibliografía 80}




\section{Introducción}

En este trabajo nos adentramos en el campo de la subjetividad para ver cómo se incorpora al análisis lingüístico desde dos vertientes: su manifestación formal, en la modalidad, o a través de la función que las emociones cumplen en la actividad argumentativa y en la calificación como cortés o descortés de un mensaje ${ }^{1}$. Lo analizaremos en dos formatos discursivos: el texto político ${ }^{2}$, donde se convierte en un arma argumentativa más, y el publicitario, que utiliza el argumento emotivo como refuerzo y mecanismo para captar de forma efectiva al usuario.

Tras una revisión teórica y un estudio de sus funciones pragmáticas (punto 2), nos centraremos en dos formatos textuales específicos: el texto político (3) y el publicitario (4), para mostrar cómo en el discurso público se acude a la subjetividad con una doble función: como intensificador o atenuador de la argumentación y de la cortesía, o como argumento falaz para conseguir los fines comunicativos. De esta manera esta variable se justifica definitivamente como un instrumento pragmático de primer nivel.

El marco teórico de este trabajo se sitúa en las teorías de la argumentación en la lengua (Anscombre-Ducrot 1983, Ducrot 1984, 1995, Fuentes-Alcaide 2002), y la cortesía verbal (Brown-Levinson 1987, Haverkate 1984, Bravo-Briz 2004, Bravo ed., 2005, Locher-Watts 2005). La interrelación de ambas nos permite arrojar una nueva luz sobre este tema dentro de la lingüística pragmática (Fuentes Rodríguez 2000).

\footnotetext{
${ }^{1}$ Este trabajo es fruto de dos proyectos de investigación: “(Des)cortesía y medios de comunicación: estudio pragmático" (FFI 2009-10515), concedido por el Ministerio de Ciencia e Innovación para el trienio 2010-2012, y el Proyecto de Excelencia concedido por la Junta de Andalucía: "La perspectiva de género en el lenguaje parlamentario andaluz" (HUM 5872, 2011-2014), ambos cofinanciados con fondos FEDER.

${ }^{2}$ Cfr. Lo Cascio (1998, 244 y ss.), Perelman-Olbrechts-Tyteca (1989, 65 y ss.), Charaudeau (2008), Van Dijk (2000a, 71 y ss.), Van Eemeren-Garssen-Meuffels (2009, cap. 3).
} 
2. Marco teórico y metodología de análisis: El concepto de subjetividad y su inscripción en la teoría lingüística

El concepto de subjetividad, entendido en sentido amplio, ha sido tratado de diversos modos. Finegan $(1995,4)$ lo sitúa en tres campos, aunque hay que decir que se centra en el estudio de la subjetividad y la "subjectivisation":

(1) a locutionary agent's perspective as shaping linguistic expression;

(2) a locutionary agent's expression of affect towards the propositions contained in utterances;

(3) a locutionary agent's expression of the modality or epistemic status of the propositions contained in utterances.

Dentro de la Pragmalingüística, se considera una variable codificada en las lenguas, que actúa en el plano de la realización lingüística, marcando la relación con el hablante. Es el concepto de modalidad, que encontramos perfectamente expuesto en la obra de Bally de $1944(1965)^{3}$. Para él, el enunciado se compone de modus + dictum. Y ese modus caracteriza, define y constituye el enunciado realizado (Fuentes Rodríguez 1991 a y b, Fuentes-Alcaide 1996). Actúa, pues, como un marcador lingüístico.

La modalité est l'âme de la phrase; de même que la pensée, elle est constituée essentiellement par l'opération active du sujet parlant. On ne peut donc pas attribuer la valeur de la phrase à une énonciation tant qu'on n'y a pas découvert l'expression, quelle qu'elle soit, de la modalité (Bally 1965: 36)

Otros trabajos entienden subjetividad como equivalente a sentimientos $\mathrm{y}$ emoción. Caffi-Janney (1994), por ejemplo, analizan la interrelación entre las categorías psicológicas de la emoción (evaluación, potencia y actividad) y las categorías lingüísticas emotivas (proximidad, cantidad, evaluación, volición, especificación, evidencialidad) ${ }^{4}$, pero no precisan ni sus manifestaciones lingüísticas ni la función argumentativa que puedan tener en un discurso. La Lingüística sistémica de Halliday (1979), por su parte, los sitúa dentro del plano interpersonal del lenguaje. En esta línea se inscriben los trabajos de Martin-White (2005) y su "appraisal theory",, que ha tenido

\footnotetext{
${ }^{3}$ En el mismo sentido Zavadil (1968: 63), Kovacci (1986: 91) y Martin (1980: 65). Cfr. KerbratOrecchioni (1986), David-Kleiber (eds, 1983) y Palmer (1986), entre otros.

${ }^{4} \mathrm{Su}$ estudio analiza las aportaciones de Labov-Waletzky (1967), Hymes (1972), Gumperz (1977), Chafe (1982), Irvine (1982), Labov (1984), Tannen (1984), Ochs (1986), Schiffrin (1987), Hübler (1987), Volek (1987), Fairclough (1988), Biber-Finegan (1989), Ochs-Schieffelin (1989), Wowk (1989), Besnier (1990), Katriel-Dascal (1989), Lutz (1990), Arndt-Janney (1991).

${ }^{5}$ Los fundamentos de esta teoría se encuentran en Halliday (1994) y en los presupuestos de Bajtin (1982), sobre todo en los conceptos de dialogismo, polifonía, heteroglosia e intertextualidad. En Martin-White (2005, 34-35) se precisan sus campos de análisis: “(...)appraisal is one of three major discourse semantic
} 
una gran acogida. La evaluación, en dicha perspectiva, afecta a la expresión de los sentimientos $\mathrm{u}$ opinión del hablante, a la interacción con el interlocutor y a la organización discursiva ${ }^{6}$. En otra dirección se encuentra el enfoque argumentativo o sociopragmático (Walton 1998, Woods-Walton 1989, Plantin 1998, Kienpointner 2008a y b, Isik-Güler/Rühi 2010) ${ }^{7}$ o el análisis aplicado a diferentes tipos discursivos (cfr., por ejemplo, Bolívar 1997, 2001, 2006).

En nuestro caso, queremos pararnos a considerar cómo utiliza el hablante la subjetividad en la interacción para marcar la cortesía o descortesía ${ }^{8}$, es decir, para establecer una relación de armonía con el receptor o atacar su imagen. Permítasenos decir, en este sentido, que entendemos la cortesía como una variable de la relación social, pero desde el punto de vista lingüístico es un mecanismo que actúa en el plano argumentativo (Fuentes Rodríguez 2009a). El hablante usa la cortesía o la descortesía para conseguir algo del oyente, ya sea a través de la alabanza de su imagen, o destruyéndola (Brown-Levinson 1987). De ahí que tengamos que situar todo lo que sigue en el ámbito de una teoría de la argumentación (Anscombre-Ducrot 1983, Lo

resources construing interpersonal meaning (alongside involvement and negotiation). Appraisal itself is regionalized as three interacting domains - 'attitude', 'engagement' and 'graduation'.

Attitude is concerned with our feelings, including emotional reactions, judgements of behaviour and evaluation of things. Engagement deals with sourcing attitudes and the play of voices around opinions in discourse. Graduation attends to grading phenomena whereby feelings are amplified and categories blurred. Martin-White (2005) nos remiten a Eggins (2004/1994), Halliday (2004/1994), Matthiessen (1995), y Martin 1992- Rose (2003).

6 “"(...)the theory is concerned more particularly with the language of evaluation, attitude and emotion, and with a set of resources which explicitly position a text's proposals and propositions interpersonally. That is, it is concerned with those meanings which vary the terms of the speaker's engagement with their utterances, which vary what is at stake interpersonally both in individual utterances and as the texts unfolds cumulatively" (http://www.grammatics.com/appraisal/AppraisalOutline/AppraisalOutlineWPFiles.html). Cfr. Martin (2000), y Hunston-Thompson (2000) para una revisión de estos planteamientos, y la web: http://www.grammatics.com/appraisal, en la que encontramos aportaciones e incluso una síntesis y actualización de la propia teoría. Otros trabajos en los que podemos encontrar una exposición y aplicación de la misma son White (2000, 2002, 2003, 2004), Martin (1995, 2003, 2004), Painter (2003), o Kaplan (2004) y González Rodríguez (2011). El tema de la evaluación es ahora un campo de análisis fructífero, donde abundan los acercamientos desde diversos puntos de vista. Consúltese, asimismo, Lemke (1992, 1998), Englebretson (ed., 2007), la perspectiva de Kärkkäinen (2003), o los estudios encuadrados en Niemeier-Dirven (eds. 1997).

${ }^{7}$ Bamberg (1997), por su parte, plantea la relación lenguaje-emoción en un doble sentido: cómo expresar las emociones, o cómo el lenguaje nos explica la naturaleza de la emoción.

${ }^{8} \mathrm{La}$ teoría de la cortesía verbal ha tenido un gran desarrollo en la pragmática actual. Cfr. Brown-Levinson (1987), Haverkate (1984), Bravo (2001, ed. 2005), Bravo-Briz (eds., 2004), Kaul de Marlangeon (1992, 1995), Culpeper (1996), Placencia-Bravo (eds., 2002), Placencia (2007), Bousfield- Locher (2008), entre otros, así como C.Fuentes (2011a) y C.Fuentes-E.Alcaide- E.Brenes (eds. 2011). 
Cascio 1998, Fuentes-Alcaide 2002) ${ }^{9}$.

En este entorno (la argumentación cortés o descortés), la manifestación de la subjetividad del yo locutor puede funcionar como:

- Un elemento codificado lingüísticamente (la modalidad), que actúa como un calificador de la argumentación (Toulmin 1958, Lo Cascio 1998, Ducrot 1995, Rocci 2009, Enis 2006) e intensifica, atenúa o invierte el valor cortés o descortés de un elemento.

- Un argumento, y en este sentido entra dentro de las falacias argumentativas. Se sitúa en el "pathos" y afecta al "ethos" de la comunicación (Perelman- Olbretchs-Tyteca 1989, 694-695, Lo Cascio 1998, 244 y ss.).

Son, pues, dos direcciones diferentes en el enfoque pragmático: la primera más ligada a los elementos pragmalingüísticos, la segunda al comportamiento y la relación interactiva. Veámoslos con detenimiento.

\subsection{La modalidad lingüística}

Desde el punto de vista pragmalingüístico y desde una teoría de la enunciación (Bally, Benveniste), el tema de la modalidad es tratado como una dimensión pragmática que se manifiesta a través de operadores específicos: los modalizadores. Estos actúan dentro del enunciado y, aparte de mostrar la actitud subjetiva del hablante, pueden ser empleados con un fin argumentativo. Algunos autores han resaltado este hecho (Lo Cascio 1998). Anscombre-Ducrot (1983) hablan de operadores argumentativos (que marcan la orientación o fuerza de un segmento) y de modificadores realizantes (MR) y desrealizantes (MD, Ducrot 1995) ${ }^{10}$. Los primeros intensifican la fuerza argumentativa, y los últimos la atenúan o invierten la orientación de un elemento. Podemos verlo en el siguiente fragmento de comentarios en la web, utilizado para publicitar un hotel. Las

\footnotetext{
${ }^{9}$ Cfr., asimismo, sobre argumentación, los siguientes trabajos: Perelman-Olbrechts-Tyteca (1989), Toulmin (1958), Plantin (1998), Van Eemeren -Grootendorst (1992, 2004), Van Eemeren et al. (eds., 2007), Van Eemeren-Garssen (eds., 2009), Van Eemeren-Garssen-Meuffels (2009), Lo Cascio (1998), Hitchcock-Verheij (eds., 2006), entre otros.

${ }^{10} \mathrm{Cfr}$., asimismo, la reciente publicación sobre marcadores argumetativos de Van Eemeren et al. (eds., 2007).
} 
valoraciones, o pretendidas opiniones de usuarios, se usan argumentativamente para incitar al usuario a reservar en dicho hotel:

(1) "Un hotel encantador en una ubicación fantástica. Sin duda me volveré a alojar allí de nuevo"

\section{Comentado el 1 diciembre 2010}

Me alojé en el hotel D'Aubusson por 7 días y disfrutamos muchísimo de la experiencia. El personal era amable y servicial y las habitaciones estaban muy limpias, eran espaciosas y cómodas. Nos alojamos en una suite de 2 habitaciones con el suelo para huéspedes muy agradable y era precioso. La decoración en la sala y la sala de desayuno era impresionante y el bar del hotel era muy divertido, con 3 noches vivas de la música la semana. La ubicación del hotel es fantástica, con muchos restaurantes cerca y a un corto paseo de la estación de metro y varios de las atracciones de París. Sin duda me alojaré allí la próxima vez que esté en París. ( http://www.tripadvisor.es/ShowUserReviews-g187147-d194308-r88732658Hotel_d_Aubusson-Paris_Ile_de_France.html\#CHECK_RATES_CONT, última consulta $8 / 2 / 201 \overline{1})$

El hablante expresa su evaluación a través de adjetivos: encantador, fantástica, amable, servicial, espaciosa, cómodas, agradable, precioso, impresionante, divertido, o en el contenido de verbos como disfrutamos. El significado léxico se emplea, pues, como modalizador y como argumento: elegimos términos valorativos positivos (relativos al afecto o apreciación, en términos de la teoría de la evaluación) en grado elevado o recurrimos a la intensificación con medios gramaticales (sufijos en muchísimo, ladito), a modificadores adverbiales (intensificadores como muy: muy limpias, muy divertido) o el reafirmativo $\sin d u d a^{11}$, que da más fuerza a la decisión final.

Cortesía y argumentación aparecen entrelazados en el tratamiento de estos operadores de modalidad. Así, algunos modalizadores se consideran especializados en la expresión de la cortesía. Un caso concreto es por favor, que actúa como atenuativo de la descortesía de un acto impositivo:

(2) Cuando pueda, entregue esto al director, por favor

Se trata de un operador modal con esta función argumentativa cortés. En este enunciado también aparece la oración temporal cuando pueda que limita el hecho de entregar el pedido a la disponibilidad del oyente, y con ello el hablante no se impone a él. Su uso frecuente en estos contextos de petición hace que incluso pueda usarse cuando pueda sin el mandato. En un bar podemos emitir esta secuencia, sin ningún otro añadido, para

\footnotetext{
${ }^{11}$ Cfr. Fuentes Rodríguez (2009b). El DRAE lo hace equivaler a "indudablemente, con toda seguridad" (http://www.rae.es, s.v.). Este adverbio tiene una función reafirmativa en español.
} 
solicitar que nos atiendan. En este caso, al no estar completamente gramaticalizado con este valor, actuaría como un modificador desrealizante ${ }^{12}$.

También los apelativos, como anda ${ }^{13}$, se utilizan con un valor de cortesía, buscando la empatía del receptor y atenuando la imposición del acto.

(3) Déjame el ordenador un ratito, andaaa ${ }^{14}$.

Esta función es reconocida no solo para los operadores modales, como los anteriores, sino que se extiende a "estructuras oracionales modalizadas". Entre ellas la interrogación ocupa un lugar preeminente. Generalmente se la ha ligado al acto de habla de la pregunta. Sin embargo, cuando las condiciones contextuales varían (Searle 1969), sirve como estrategia modalizadora de otros contenidos. Así, se usa generalmente para la petición cortés:

(4) ¿Podrías encargarte tú de enviar estos mensajes?

(5) ¿Te importaría llamar a Lucía y pedirle el certificado?

O el consejo:

(6) ¿Por qué no intentas descansar un poco? ${ }^{15}$.

Pero en otros contextos la interrogación puede expresar actos descorteses:

(7) ¿Te parece bien este comportamiento?

Cuando se lo decimos a alguien ante una salida de tono o una acción reprobable, es una recriminación y, por tanto, descortés ${ }^{16}$. Igual ocurre con las siguientes interrogaciones:

\footnotetext{
${ }^{12}$ A diferencia de los operadores, como por favor, que son elementos fijados ya en la lengua con esta función de cortesía o descortesía. Cfr. Fuentes Rodríguez (2003) para la diferencia conector/operador y Fuentes-Alcaide (2002, 55-73) para distinguirlos de los modificadores realizantes y desrealizantes.

${ }^{13}$ Para ver el valor de esta unidad, cfr. Fuentes Rodríguez (2009b).

14 El alargamiento vocálico al final supone cierta actitud suplicante, y delimita claramente el valor mitigador del elemento. En otros contextos, sin embargo, este valor puede quedar menos explícito. Compárese el siguiente ejemplo: "Come, anda. Hemos terminado ya" (CREA, Esta noche cruzamos el Mississippi, 23/10/96, Tele 5) con "Venga, esta vez no me suicido. No, hazlo por mí, anda. A petición tuya bonita, amiga, pero la próxima vez que me pase me tiro al metro, Reme. Hija mía, qué sanguinaria eres (CREA, Corazón, corazón, 19/10/96, TVE 1). En el segundo caso el contexto apoya la atenuación, mientras que el primero puede entenderse como una intensificación, un MR del mandato.

${ }^{15}$ Estos tres enunciados combinan varios mecanismos: a) la estructura interrogativa total o parcial (ipor qué no?), b) el condicional, c) el uso de verbos como importar. Cfr. Fuentes Rodríguez (2010a) para ver la función cortés o descortés de estos procedimientos.

${ }^{16}$ Frente a "¿Te parece bien este comportamiento?”, cuando lo dirigimos a otro adulto, al que pedimos una opinión. En este caso es una pregunta real.
} 

(8) ¿Tú sabes cuánto ha comido?
(9) ¿Es que no ves que lo vas a tirar?
(10) ¿Estarás a gusto ahora, no?

Emitidas en una situación de enfrentamiento, con un tono elevado y una actitud de enfado por parte del hablante, se interpretan como formas de recriminación ${ }^{17}$.

Algunos mecanismos actúan incluso como intensificadores de la descortesía:
(11) ¿Eres imbécil o qué?
(12) ¿Cuántas veces te tengo que decir que no pongas los pies ahí?!

La primera aporta una disyunción ( o qué), y en la segunda aparece el sintagma cuántas veces que implica mucho tiempo, lo que actúa como potenciador del acto de habla.

La interrogación, como vemos, puede usarse con valor recto, como pregunta, con valores emotivos-expresivos, o con una función cortés o descortés. Esta diversidad se muestra en las viñetas de Mafalda ${ }^{18}$ :

(13) Mafalda: ¿Qué decís, premio Nobel de la maceta?

Padre: ¿DÓNDE ESTÁ EL RESPETO QUE DEBÉS GUARDAR A TU PADRE?

Mafalda (se queda pensando): ¿En la heladera?

En esta interacción la primera interrogación es de saludo (se utiliza para garantizar una interacción cortés ${ }^{19}$ ), la segunda es una expresión de enfado, emotiva, y constituye una reprimenda. Sin embargo, el acto de habla no es descodificado por Mafalda con este valor. Ayuda el tono de voz, evidentemente, y los elementos paralingüísticos. Pero Mafalda interpreta la interrogación parcial como tal (o parece hacerlo, de forma irónica, para crear un efecto de sentido). Ello provoca su respuesta: ¿En la heladera?, que desarma a su "oponente".

El mandato, por su parte, se considera un acto agresivo contra el receptor, invasor de su espacio (Haverkate 1984, 1987, 1994). En el siguiente caso la reiteración y la pronunciación elevada, casi gritando, intensifica la descortesía:

\footnotetext{
${ }^{17}$ Dependen, evidentemente, del tono, la intención del hablante y factores contextuales. Cfr. Fuentes Rodríguez (2011a).

${ }^{18}$ Puede consultarse en http://mafalda.dreamers.com/

${ }^{19}$ Correspondería a una cortesía ritual, necesaria para el establecimiento de la interacción. Frente a esta existe la cortesía estratégica, que el hablante utiliza para conseguir sus fines argumentativos y proyectar una imagen persuasiva ante el otro. Para estos conceptos cfr. Fuentes Rodríguez (2010a).
} 
(14) Colaboradora [y a mí] me eso $\uparrow /$ me indigna $\downarrow / /$ y que Rubalcaba diga $\rightarrow / /$ que este país $\rightarrow / /$ el gobierno $\rightarrow \S$

Entrevistado: $\S$ perdón $\downarrow \S$

Colaboradora: $\quad \S$ ha pagado $\rightarrow / /$ DOS MILLONES/ $\quad\left[\right.$ DE EUROS $\left.\rightarrow{ }^{20}\right]$

Entrevistado: $\quad$ [Sí sí sí $(())]$

Colaboradora: $=$ para encontrar a este señor $\rightarrow / /$ millones/ [que hemos pagado nosotros $\rightarrow / /$ iME

INDIGNA! $\uparrow / /$ ¡ME INDIGNA!] (Sálvame De Luxe, Tele5, 19-11-2010)

En otras ocasiones podemos recurrir a formas asertivas para expresar un acto directivo. De esta manera reducimos la fuerza del acto de habla, al utilizar una forma indirecta (Fuentes Rodríguez 2010a). Podemos emplear el presente:

(15a) Vas al taller y le pides la factura mañana mismo.

O el futuro, menos atenuativo:

(15b) Irás al taller y le pedirás la factura mañana mismo

(16) Tendrás que reservar el hotel y cargar tú con los gastos.

Estas expresiones, de nuevo, no son solo muestras de un mandato, acto impositivo e invasivo del otro, sino que llevan añadido un contenido modal, subjetivo, de enfado o molestia. En ellas la estructura de modalización sirve bien para atenuar la descortesía (interrogación) o para intensificarla (aserción en futuro) y actúa, por tanto, como un mecanismo argumentativo ${ }^{21}$.

Esta relación entre modalidad, argumentación y (des)cortesía es de ida y vuelta. Es decir, no solo la primera está al servicio de las otras dos, sino que las expresiones consideradas descorteses en determinado contexto pueden derivar hacia una nueva expresión de la emoción. Es lo que se llama en Fuentes Rodríguez (2009a) la función modal de la descortesía. Podemos ilustrarla con este fragmento del corpus Valesco (comentado en un sentido parecido en Kienpointner 2008b):

(17) A: NO QUIERO QUE ESTÉS AGUANTANDO

B: ENTONCES ¿¡QUÉ QUIERES QUE HAGA!?/¡HOSTIA! ES QUE /¡JODER! (Briz y grupo Valesco 2002, ML.84.A.1)

Corresponde a una discusión de pareja. A pesar del tono elevado (marcado por las mayúsculas), A y B mantienen una relación íntima entre ellos que hace que el

\footnotetext{
20 Aparece a pie de pantalla: "POR PRIMERA VEZ Y EN EXCLUSIVA, HABLA EMILIO RODRÍGUEZ MENÉNDEZ TRAS DOS AÑOS PERSEGUIDO POR LA JUSTICIA ESPAÑOLA”.

21 Como ya hemos expuesto, entendemos la cortesía como una estrategia argumentativa (Fuentes Rodríguez 2009a).
} 
enfrentamiento se vea algo más atenuado de lo que las palabras sugieren. Además, en este fragmento las expresiones fuertes están, no para provocar descortesía, sino como expresión modal del hablante, para marcar enfado, molestia, y no para herir al otro.

\subsection{Emoción, argumentación y cortesía}

La otra dirección en la que se aplica el concepto de subjetividad pertenece al plano del comportamiento y la relación interactiva. En este sentido la expresión de emociones se considera inadecuada en situaciones formales y, dentro de la argumentación, la retórica las rechaza como argumentos falaces, como dijimos más arriba. Recurrir a la emoción implica, indirectamente, una carencia de razones basadas en la lógica, lo que se acerca mucho a la manipulación. Este rechazo se centra en, al menos, tres tipos argumentativos o falacias:

a) argumentum ad hominem (Lo Cascio 1998, Woods-Irvine-Walton 2004, WoodsWalton 1989) ${ }^{22}$ : consiste en desacreditar al interlocutor:

(18) No sé cómo te permites presentarte aquí después de lo que has hecho. Nos has mentido a todos, has abandonado tu puesto de trabajo y, encima, culpabas a tus compañeros de la falta de producción de la empresa.

Entre ellos encuentra Kienpointner (2008a, 248) varios subtipos que incorporan estrategias de descortesía:

1. direct personal attacks questioning the physical and mental abilities of the attacked person, often combined with insults and swearwords ("abusive ad hominem");

2. accusations of being inherently and permanently biased ("poisoning the well");

3. reproaches concerning the membership within a social group, which, according to the speaker, has negative properties ("guilt by association").

b) argumentum ad baculum: el hablante intenta convencer con una amenaza al interlocutor:

(19) Oiga usted, no tiene derecho a tratarme así. Piénselo bien antes de hacer acusaciones, no vaya a tener una sorpresita a final de mes.

\footnotetext{
${ }^{22}$ Otros lo llaman argumentum ad personam y consideran argumentum ad hominem el que desacredita lo que rodea al interlocutor (Lo Cascio 1998). Pero Woods-Walton (1989) hablan solo de este último. Recientemente Van Eemeren-Garssen-Meuffels (2009) discuten la posibilidad de la existencia de un argumentum ad hominem falaz y otro razonable, dependiendo de la situación comunicativa. Cfr. el capítulo 3 de esta obra titulado: "Ad hominem fallacies : an exemplary study" (51-83).
} 
c) argumentum ad misericordiam: el hablante no defiende un argumento, sino que se adhiere a él por compasión:

(20) Hombre, no lo trates así, es un pobre hombre. Hace lo que puede.

En ellos el ataque a la persona se utiliza para desacreditar su razonamiento, una maniobra manipuladora que provoca claramente una descortesía más o menos explícita. Sin embargo, Kienpointner (2008a) no limita el uso de la emoción a una asociación con las falacias:

Emotional arguments need not be fallacious nor are they always formulated in impolite ways. However, certain fallacious subtypes of emotional arguments involving appeals to negative emotions such as fear, hate or contempt tend to be formulated in an impolite way. As competitive strategies are employed both at the content level (fallaciousness) and at the interpersonal level (impoliteness), the non-cooperativity of these interactions is increased considerably. Accordingly, arguments which are both fallacious and impolite can be called "destructive arguments". It has also been shown, however, that sometimes even fallacious arguments involving positive emotions such as pity can be formulated in an impolite way. Finally, in certain exceptional cases even rude and fallacious arguments are not (totally) destructive, because they ultimately serve some vital interests of the opponent. (Kienpointner 2008a: 263)

Para él no todo argumento emocional lleva a la descortesía, ni toda falacia es destructiva, ya que puede ir en beneficio del receptor.

Kienpointner (2008 a y b) establece una relación entre los tres conceptos: cortesía-argumentación-emociones. Según él, y siguiendo a Watts (2003, 96 y ss.), a las 3 categorías que influyen en la cortesía según Brown-Levinson (1987), poder, distancia social y contexto sociocultural, hay que añadir la relación emocional entre los participantes (Watts 2003, 96 y ss.). Así, aunque Brown-Levinson (1987) se basan en un modelo de persona racional, debe tenerse en cuenta la emoción porque:

a) No hay un límite tan tajante entre emoción y razón, la emoción puede llevar a la racionalidad: por ejemplo, la compasión lleva a luchar contra la injusticia.

b) Los tres factores de Brown-Levinson implican también cierto grado de emoción: una gran distancia de poder provoca ciertas emociones, el exceso de distancia o, por el contrario, el acercamiento pueden provocar la simpatía...

c) Leech (1983) integra emoción y (des)cortesía, aunque sólo en dos máximas: la de simpatía y la de antipatía.

d) La (des)cortesía se utiliza para modificar las emociones. 
e) Las emociones son un factor más para determinar la (des)cortesía (Kienpointner 2008b).

(Des)cortesía y emociones están, pues, en relación dialéctica: las emociones pueden provocar la descortesía, o la descortesía puede crear ciertas emociones. Por ejemplo, no responder en una conversación se interpreta como descortés, pero puede estar motivado por una emoción: la vergüenza. Interpretamos, pues, en un contexto interactivo de cortesía lo que es pura subjetividad. Igualmente usamos la razón, un argumento ad hominem, para rechazar a alguien. Así cuando mostramos una emoción fuerte de forma racional la atenuamos. Por ejemplo, en la tribuna del Parlamento no esperaríamos oír una expresión del tipo:

(21) Por Dios, ¡qué mierda de persona!

sino una forma más indirecta, una expresión mitigada:

(22) Me molesta bastante su actitud

El primer enunciado es más fuerte que el segundo, la emoción intensifica el rechazo, así como las expresiones lingüísticas empleadas (la interjección, la exclamación y el término valorativo del insulto). Al convertirlo en un enunciado aseverativo la emisión lingüística es más atenuada, aunque la intención siga siendo de enfrentamiento.

También la sorpresa puede usarse para mostrar el desacuerdo:

(23) Presentador: Pero ¿Has llorado un poquito pensando $\rightarrow$ ? $\S$

Entrevistada:
llorar!? $\uparrow /$ ¡POR FAAVOR!! § (RISAS)

$\S$ ¡¿Pero qué dicee?! ¡¿Por qué voy a

Colaboradora: $\quad \S$ ¡Es que a Jorge gusta que llores! ¡Hija mía! $\uparrow / ¡ T u ́$ dile que síii! $\uparrow$

Entrevistada: $§$ Por favor! $\rightarrow$ / SI NO HE LLORAOOO NI YO AL DESPEDIRME DE MI

MADRE CUANDO ENTRABA PAAA PA TRES MESES $\uparrow /$ ¡Voy a llorar! $§$ (Sálvame, 3-22010)

Evidentemente, hay marcas que nos ayudan en la interpretación. La entonación en ¿Pero qué diceee? lo convierte en una fórmula de desacuerdo y rechazo a lo dicho por el otro interlocutor, así como muestra la sorpresa o lo inadecuado que le parece su emisión. POR FAAVOR, emitido en tono elevado de voz, en vez de actuar como atenuante cortés de la petición, muestra la extrañeza y la oposición del hablante, además de intensificar la emoción. 
Al mismo tiempo, tenemos casos de inversión: el uso de "mock impoliteness" (Culpeper 1996) o "banter" de Leech (1983). Por ejemplo, saludar a un amigo diciéndole cabrón se debe no sólo a la coloquialidad, sino a la relación cercana entre los interlocutores que permite la expresión de ciertas emociones positivas. Kienpointner (2008a) ya señala que la simpatía puede ser un factor importante para reducir la descortesía de un acto. $\mathrm{Y}$ es en este ámbito donde puede introducirse este factor de subjetividad.

En la investigación sobre cortesía los modelos incorporan diversos factores o filtros: la distancia social, el poder y la jerarquía, decían Brown-Levinson (1987). Otros, como Briz (2004), añaden el grado de inmediatez o coloquialidad. O bien la relación entre hablante-oyente, el contenido social, cultural, histórico, las convenciones sociales añadidas y los valores que cada comunidad maneja (Bravo 2004, Watts 2003, SpencerOatey 2000, 2005). El tipo de discurso también es fundamental (Fuentes Rodríguez 2011a). Por tanto, si entre hablante y oyente hay una relación de familiaridad, cercanía, empatía o simpatía, pueden aparecer elementos descorteses con una función diferente: en lugar de atacar la imagen del receptor sirven de elemento de afiliación. Es lo que Zimmermann (2003) usó para describir el habla de los jóvenes y lo que encontramos (Fuentes-Alcaide 2008, 2009, Blas Arroyo 2009) en casos como el siguiente:

(24) Habla con ella, tío, no seas tan inmaduro.

En este enunciado, que dirigimos a un amigo, encontramos un mandato literal, con imperativo, seguido de un insulto, pero en este contexto de confianza tanto el mandato como el insulto se desvirtúan y se convierten en mecanismo de cortesía. Es decir, el grado de confianza es un filtro que actúa como MD e invierte su calificación de descortés a cortés. Igualmente en el siguiente caso:

(25) Presentador: [QUE LO ] pasábamos todos fatal $\uparrow / /$ Que nos íbamos todos con el agua al cuello pensando: $\rightarrow$ / iPor Dios! Aqui se va a producir algo $\uparrow / \mathrm{Y}$ de repente va $\uparrow / \mathrm{y}$ me cuenta que viene Paz Padilla y la reconciliaa $\downarrow$ (RISAS COLABORADORES)(3”) / Y yo penséee $\uparrow /$ [iSerán] cabronas! (APLAUSOS DEL PÚBLICO)(4”)

Colaboradora: $\quad[(())]$

Presentador:¡PERO DE LA SIERRA DE GREDOS ¿EH?! $\uparrow /$ ¡Cabronas de la Sierra de Gredos $\rightarrow$ / (LOS COLABORADORES RÍEN) Es maravilloso $\downarrow /$ Cabronas de la Sierra de Gredos $\rightarrow /$ - (Sálvame, Tele 5, 3 -2-2010)

El fragmento señalado pertenece a la intervención del presentador en una tertulia con los colaboradores del programa. Es emitido entre risas, en ambiente distendido. Este rasgo invierte su contenido. Incluso continúa el presentador la broma al llamar a sus 
compañeras cabronas de la Sierra de Gredos ${ }^{23}$, como denominación de origen (imitando los productos alimenticios). Y los colaboradores ríen, lo que demuestra que no lo han entendido como una evaluación negativa.

En estos casos no es sólo el contexto de confianza el que invierte el valor del supuesto insulto $^{24}$, que pasa de descortés a cortés, sino que también es una muestra de emoción, un argumento subjetivo, ya que el presentador emplea la familiaridad, la simpatía, como argumento.

Las emociones pueden tener efectos positivos o negativos en la conversación. Pero esto no significa que una emoción positiva provoque cortesía y una negativa descortesía. Algunos grupos sociales pueden considerar un debate exacerbado como cortés porque muestra el interés en lo dicho: lo que llama Tannen (1984) "involvement" y "sociable rudeness" Kienpointner (1997). El enojo y la cólera pueden interpretarse como una forma de proximidad. Por tanto, la relación no es biunívoca:

- la descortesía puede estar justificada en un contexto de diálogo. Una intervención de inicio con expresiones descorteses legitima su presencia en la reacción

- las emociones positivas, corteses y descorteses, dependen del contexto sociocultural en que estemos

- ciertas emociones pueden utilizarse con fines estratégicos: podemos usar un cumplido para conseguir algo del otro.

(26) Me ha encantado su discurso. Ha sido usted oportuno, claro y brillante. Nadie podría haberlo dicho mejor. Soy militante en el partido y le admiro muchísimo. Mi nombre es... (forma de presentarse para que le suene su nombre en el próximo comité del partido)

El hablante puede recurrir a argumentos emocionales como el argumento ad hominem o a sentimientos como la pena (Kienpointner 2008a) para provocar efectos descorteses (Walton 1992 y Plantin 1998). Por ello, Kienpointner incluye en su definición de descortesía el aspecto emotivo:

Impoliteness/Rudeness is a kind of prototypically non-cooperative or competitive communicative behaviour:

\footnotetext{
${ }^{23}$ También puede ser debido a que el moderador intenta corregir su enunciación dado el horario en que se emite, que prohíbe la expresión de términos soeces.

${ }^{24}$ Actúa como MD.
} 
which destabilizes the personal relationships of the interacting individuals and thus makes it more difficult to achieve the mutually accepted goal of the interaction or makes it difficult to agree on a mutually accepted goal in the first place;

_ which, more particularly, creates or maintains an emotional atmosphere of mutual irreverence and antipathy, which primarily serves egocentric interests;

- which is partially determined by concepts of power, distance, emotional attitudes and cost-benefit scales which are generally accepted in a speech community (Kienpointner 2008a, 245).

En suma, la subjetividad como campo designativo del hablante se inserta en el sistema lingüístico a través de varias vías:

a) se hace forma lingüística (modalidad): caracteriza al enunciado y lo inscribe en relación con el hablante. A su vez esta forma, en un segundo momento, se emplea como calificador (atenuador o intensificador) de la argumentación y la cortesía. Salta a la macroestructura (Fuentes Rodríguez 2000).

b) Las emociones como tal se emplean como argumento y determinan las relaciones de (des)cortesía entre los interactuantes en la comunicación. Actúan en el plano interpersonal del lenguaje (Halliday 1973).

Es decir, los sentimientos del hablante pueden hacerse instrumento lingüístico que modula el discurso (modalidad) o pueden usarse directamente en la macroestructura argumentativa.

\section{La subjetividad en el discurso político}

La presencia de la subjetividad es esperable en la conversación, ya que pertenece al ámbito privado, pero sería menos justificable en el discurso público. Sin embargo, su presencia es cada vez mayor, ya que el hablante explota este carácter de novedad (no previsible) para enriquecer su mensaje y dotarlo de una alta capacidad persuasiva ${ }^{25}$.

En contextos como el político ${ }^{26}$, no existe la relación de familiaridad entre los participantes que justifique la inclusión de las emociones. Por otro lado, la retórica,

\footnotetext{
${ }^{25}$ Para Charaudeau (2008) es una estrategia de dramatización discursiva.

${ }^{26}$ Cfr. Alvar (1997), Arce (2006), Miche (1998), Alcaide (1999), Blas Arroyo (2000 y 2003, 2011), Fernández Lagunilla (1980, 1999), Núñez Cabezas- Guerrero Salazar (2002), Hernando Cuadrado (2004), Martín Rojo (2000), Martín Rojo-Van Dijk (1997), Van Dijk (2000b, 2005, 2007), López Eire-de
} 
como hemos dicho, ha considerado su uso como un mecanismo argumentativo falaz. No obstante, la práctica habitual ha abandonado esta visión ética en favor de su alto rendimiento dialéctico. La coloquialización y no especialización del lenguaje empleado en los ámbitos públicos como modo de acercamiento (y persuasión) del ciudadano tiene mucho que ver en este empleo.

En principio, podríamos decir que las funciones que cumple la subjetividad en este tipo textual son:

a) Potenciador del enfrentamiento, MR de la descortesía, para darle más intensidad. Personaliza el ataque, lo hace más directo.

b) Elemento de fuerza de las aserciones propias.

c) Marca de autoimagen: define la función de rol del hablante frente a su adversario.

d) Calificador de los argumentos para manipular o falacias, sobre todo en el ataque $a d$ hominem.

El texto político es el ámbito preferido para la utilización de las falacias $\operatorname{argumentativas}^{27}$. En ellas la emoción se utiliza como arma en la confrontación. El que sea algo permitido hace que se rebaje su fuerza. Los políticos no intentan convencer al otro con argumentos lógicos, sino destruir su imagen, para que los ciudadanos no los voten. De ahí que el ataque personal sea fundamental. Y para ello se utiliza a veces también la emoción como apoyo ${ }^{28}$.

El enfrentamiento, y la descortesía consiguiente, se ven reducidos por el tipo de situación interactiva, por el tipo discursivo (Fuentes Rodríguez 2011a). Es lo que ocurre en los debates parlamentarios, $y$, sobre todo, en las preguntas orales ${ }^{29}$, donde el grado de subjetividad sube y se utiliza como arma arrojadiza. Por supuesto, también tenemos

Santiago Guervós (2000), Trognon-Larrue (eds., 1994), Bayley (2004), Ilie (2001, 2003 a, b, 2004), Chilton (2002, 2004), Wilson (1990), o los aparecidos en la revista Journal of Language and Politics.

27 Afirma Van Dijk (2000a, 71): "Parliamentary debates, just like any other dispute about contested points of view and opinions, are riddled with normative breaches of 'proper' argumentation, that is, with fallacies. These may pertain to any element of the argumentative event, namely to the nature of the premises, the relations among the premises and the conclusion, the relations between speaker and recipients, and so on."

${ }^{28}$ Cfr., asimismo, Fuentes Rodríguez (2010b, 2009c).

${ }^{29}$ Este formato discursivo tiene limitada su extensión en el tiempo ( 5 minutos) y dos participaciones de cada uno. Su fin es claramente polémico y el tono empleado directo y frecuentemente agresivo. Cfr. Pérez de Ayala (1996, 2001), Borthwick (1993), Franklin-Norton (1993), Fuentes Rodríguez (2011b y c, 2012). 
argumentos ad hominem, ataques directos a la persona, cuya credibilidad se intenta destruir.

En el siguiente caso, Zapatero en el Debate con Rajoy en 2008 acude a la acusación directa:

(27) Zapatero: Usted ha dicho que la primera pregunta fue de economía, y la tengo aquí y no habló de economía. Preguntó sobre la acción del Gobierno. Está engañando, engañando, no se ha preocupado de la economía. Los precios no le han interesado hasta hace unas semanas. ¿Sabe lo que le ha importado a usted la subida de los precios y la economía de las familias? Un bledo, eso es lo que le ha importado señor Rajoy, le ha importado un bledo. (Segundo debate, www.elpais.com, 4-3$2008)^{30}$

Repite está engañando, engañando, y usa la interrogación como mecanismo catafórico de focalización de la información: ¿Sabe lo que le ha importado....? Apela directamente al receptor, lo incluye en su discurso, y de paso le da fuerza a la expresión que se espera: un bledo. Este término, claramente coloquial, provoca cierta ruptura con el tono del texto, algo que aprovecha retóricamente Zapatero para acercarse al oyente, al ciudadano votante, y crearse una imagen empática con él. Coloquialidad y emoción actúan aquí de la mano.

En la siguiente pregunta oral, Soraya Sáenz de Santamaría destruye la imagen de su interlocutor con una narración de hechos denigrativos de su rol ${ }^{31}$, seguida de una serie de preguntas retóricas. Es un ataque ad hominem:

(28) La señora SÁENZ DE SANTAMARÍA ANTÓN: Muchas gracias, señor presidente.

Señor vicepresidente, el viernes estuvo usted más Rubalcaba que nunca. Mientras toda España se alarmaba con los datos del paro, su señoría se deshacía en explicaciones de por qué había caído tanto su valoración personal en el CIS. Esa respuesta la llevaba muy bien preparada; para quien no tuvo respuesta es para los casi 5 millones de parados, o para la mitad de los jóvenes españoles que están sin trabajo, o para 1.400.000 familias que tienen a todos sus miembros en el paro. Esas son las preguntas que se hacen todos los españoles. Pero las excusas, que no las respuestas del Gobierno, son siempre las mismas. ¿Cuántas veces les hemos oído decir que lo peor ha pasado? ¿Cuántas veces han jurado, primero, que el paro no iba a llegar a los 3, después a los 4 y ahora a los 5 millones de parados? ¿Cuántas veces, como al señor Zapatero, les oiremos repetir que el paro ha bajado en el mes de abril y que es el inicio del final de la crisis? También bajó en abril de 2010 y dijeron exactamente lo mismo, y mire cómo estamos ahora. ¿Piensa el señor Rubalcaba que puede sacar a España de la crisis un Gobierno en el que ya no cree nadie? (Aplausos.)- (DSCD ${ }^{32}$ 241, 4-5-2011, 7).

\footnotetext{
${ }^{30}$ Cfr. Fuentes Rodríguez (2009d y 2011b).

${ }^{31}$ Cfr. Brown-Levinson (1987), Goffman (1959, 1967), Bravo (2001, 2005), Bravo-Briz (2004), Blas Arroyo (2003), Harris (1991, 2001), Fuentes Rodríguez (2011c y d).

${ }^{32}$ DSCD: Diario de Sesiones del Congreso de los Diputados. Gobierno de España.
} 
Incluso utiliza el nombre propio como calificativo, como denominativo de una característica: el viernes estuvo usted más Rubalcaba que nunca. Con ello expresa claramente el rechazo, y una evaluación despreciativa dirigida a su receptor y su grupo parlamentario.

Recurrir directamente a acusar al interlocutor es lo más frecuente en la argumentación parlamentaria, que, de este modo, se convierte en falaz, incorrecta (Woods-Irvine-Walton 2004, Woods-Walton 1989, Plantin 1998, Lo Cascio 1998, Lausberg 1993, Perelman-Olbretchs Tyteca 1989, Van Eemeren-Garssen-Meuffels $(2009 \ldots)^{33}$. Podemos verlo en el siguiente enfrentamiento en el Parlamento de Andalucía entre la sra. Oña, del Partido Popular, y la consejera de Hacienda y Administración pública:

(29) La señora OÑA:

(....)Por tanto, estos pagos evidencian su engaño, señora Consejera. Contablemente, o no, usted está engañando. ¿Que se proteja con la contabilidad? Usted está engañando.

¿Usted sabe lo que se le pregunta? ¿Ustedes han pagado por intermediario? Sí, tendría que haber respondido si usted fuera una política sincera. Pero no lo está siendo.

Por tanto, usted sabe que las comisiones ascienden en muchos casos al 7\% del valor de los ERE y salen de ese fondo de reptiles, que es como la bolsa de Mary Poppins. ¿Se acuerda usted de niña, señora Consejera? Salía todo. Pues, del fondo de reptiles sale todo: salen las comisiones, pero es que salen también... O sea, sale todo el expolio de dinero público que ustedes están haciendo con los andaluces. Se han destinado a los ERE fraudulentos, a subvenciones que acordaban en mítines entre amigos, en conversaciones telefónicas. Han dado créditos a empresas porque sí, porque son conocidos suyos, porque son familiares cercanos. Han pagado nóminas de negocios en bancarrota porque eran sus amigos. Todo eso ha salido del fondo de reptiles, un expolio en toda regla.

Y esa trama del robo incluye, señora Consejera, aunque usted lo niegue con facturas aquí que lo demuestran, el pago de comisiones. Tiene usted un segundo turno, tiene la posibilidad de rectificar. Sea honesta por una vez. [Aplausos.] (DSPA 120, 26-5-2011, 33)

La diputada acusa de hechos muy negativos a la Consejera: engaño, insinceridad, fraude, expolio... Provoca la minusvaloración de su imagen como política, de su rol como alcaldesa. A ello responde la Sra. Martínez Aguayo también con un ataque ad hominem:

(30) La señora MARTÍNEZ AGUAYO, CONSEJERA DE HACIENDA Y ADMINISTRACIÓN PÚBLICA

- Señoría, también con el máximo respeto, pero la misma claridad, resulta sorprendente su manera de falsear la realidad, su manera de falsear. Yo creía que usted, alcaldesa —recién elegida nuevamente-, sabría distinguir perfectamente lo que es una factura de lo que es una

\footnotetext{
${ }^{33}$ Cfr. Fuentes-Alcaide (2002).

${ }^{34}$ DSPA: Diario de Sesiones del Parlamento de Andalucía.
} 
carta. Si usted no sabe eso, en qué manos están los señores de su pueblo. Me parece sorprendente. Habrá que ver, entonces, su contabilidad, cómo la reflejan. (idem)

En este enfrentamiento se recurre a la subjetividad como estrategia: la obligación en el discurso de la sra. Oña (tendría que haber respondido si usted fuera una política sincera. Pero no lo está siendo), o la exhortación al final (Sea honesta por una vez). Son imprecaciones a su interlocutora. Asimismo, utiliza una comparación con un hecho propio del mundo infantil: la bolsa de Mary Poppins. De este modo, pretende darle más fuerza a su argumentación $y$, al mismo tiempo, crear un sentimiento de simpatía en cierto sector del público. Desautomatiza el discurso político, incluyendo un nuevo campo de referencia, no esperado, un nuevo universo de discurso en el que contextualizar la metáfora. El esfuerzo interpretativo para establecer la relevancia es mayor, ya que son dos campos alejados cognitivamente. Con ello consigue (o pretende conseguir) una imagen de oradora brillante y eficaz, a través de esta comparación novedosa. Esto puede tener, no obstante, un efecto distinto según el receptor: para unos puede ser brillante, para otros inadecuado. Su interlocutora, la Sra. Martínez Aguayo, acude a la sorpresa: resulta sorprendente... Me parece sorprendente, para intensificar el ataque.

Dirigida también a esta consejera encontramos otro ataque a la imagen, apelando a los sentimientos:

(31) El señor FERNÁNDEZ DE MOYA ROMERO

- Muchas gracias, señor Presidente.

Señora Consejera, no se enfade que solo había dado por formulada la pregunta. (DSPA 120, 35)

El sr. Fernández de Moya comienza su intervención de réplica con esta apelación. Hace inferir que la Consejera es una persona con el enfado a flor de piel, que no domina su agresividad, y que no actúa de forma oportuna o adecuada a su función política. La hace aparecer como impulsiva, dominada por los sentimientos. Estos son utilizados, como vemos, como la base de la argumentación, aún más falaz que en otras ocasiones. Destruye su imagen, aunque ella, la Consejera, había respondido a su pregunta de pagos a proveedores ofreciendo datos:

(32) La señora MARTÍNEZ AGUAYO, CONSEJERA DE HACIENDA Y ADMINISTRACIÓN PÚBLICA

-Mire, señoría, el Consejo de Política Fiscal y Financiera no ha adoptado ningún acuerdo relativo al calendario de pagos a proveedores. Lo que ha acordado el Consejo es un suministro de información periódica para poder hacer un estudio diferencial entre las diferentes comunidades 
autónomas. Y a este respecto, que es lo que ha acordado el Consejo — se lo explico otra vez, ha acordado esto, no otra cosa-, estamos elaborando la información mencionada para mandarla antes del plazo fijado. (idem)

La Consejera no ha dado pie a esa conclusión, que siembra la duda de forma maliciosa.

Otras veces se recurre a formas indirectas que, sin embargo, se potencian y adquieren más fuerza descortés:

(33) La Sra. CRESPo DÍAZ (...)El Partido Popular ya se ha posicionado en el Tribunal Constitucional, pero es un hecho gravísimo, teniendo en cuenta que es un nuevo mazazo, porque el primero lo dieron en el agua, con el IVA, que han pasado el gravamen del $7 \%$ al $8 \%$, y ahora esta nueva subida del agua, otro mazazo al bolsillo de los andaluces y andaluzas. Y, cuidado, como grava el consumo, lo paga lo mismo el parado que el rico, y, por tanto, vuelven a ir contra los más débiles con este impuestazo. $Y$, por ello, señora Consejera, le invitamos, esta mañana, a reflexionar de nuevo. Nada más y muchas gracias. (DSPA 120, 37)

Ese le invitamos es una imposición y una exigencia. El contexto precedente lo explica.

También el humor tiene cabida en el argumentario de un político, como forma de desequilibrar el tono discursivo y darle más frescura. Lo vemos en el texto siguiente de Pérez Rubalcaba:

(34) El señor VICEPRESIDENTE PRIMERO DEL GOBIERNO Y MINISTRO DEL INTERIOR (Pérez Rubalcaba): Está visto que hoy voy a recolectar interpretaciones electorales diversas; esta última todavía me llama más la atención. Los ciudadanos, convenientemente estimulados por su insistencia parlamentaria - me ha hecho usted cuarenta y dos veces esta misma pregunta - han decidido votar otras listas distintas de las del Partido Socialista. Como en el caso de la señora Sáenz de Santamaría tomo buena nota de esta original interpretación electoral.

Le reitero lo que le vengo diciendo sesión tras sesión. Efectivamente, usted lo ha señalado, y es verdad, fueron detenidos, fueron encarcelados y hoy están procesados todos los que estaban implicados en ese asunto y en su momento serán juzgados. De eso habla usted poco, pero esa es la realidad de lo que pasó en los meses de mayo y junio del año 2006. Le diré dos cosas más. Le confieso que ayer no tuve muchas buenas noticias en el día, pero por la noche, cuando acabe un día duro de trabajo iba a prepararme las preguntas parlamentarias y por primera vez, fíjese, tuve que esbozar una sonrisa porque vi la suya y me acordé de una canción infantil de mis tiempos (Rumores.) que me reconcilió... Se acuerda usted? La de Bartolo con la flauta y el agujero solo? (Risas.) Eso es lo que usted me recuerda. Le diré una cosa más. En estos días pasan muchas... (Rumores.) Sí, sí. Se acuerda? Bartolo, el agujero... (Rumores.-Risas.) (DSCD 247,25-5$2011,10)$

Recurre a una canción infantil para ilustrar su rechazo y su minusvaloración. El mismo efecto se consigue en el caso siguiente con la utilización de un lenguaje coloquial: ustedes fueron... del bracete de la extrema derecha... Y el Supremo les dio un revolcón.

(35) El señor VICEPRESIDENTE PRIMERO DEL GOBIERNO Y MINISTRO DEL INTERIOR (Pérez Rubalcaba): Muchas gracias, señor presidente.

Quiero hacer dos matizaciones previas. Una primera es que la sentencia, como usted sabe, no entra en el fondo del asunto. La sentencia lo que le dice a la junta es que tiene que completar un trámite administrativo. Y una segunda es que la sentencia no es firme. Eso quiere decir que se puede recurrir, y acatar esa no firmeza también es parte del acatamiento de la sentencia. Por tanto, empiece por acatarla, señor Tarno. 
En tanto la Junta de Andalucía resuelve, déjeme que le recuerde una cosa que ya sí sabemos: ustedes fueron al Supremo con este asunto, por cierto, del bracete de la extrema derecha (Un señor diputado: !Hala!-Un señor diputado: Sí, sí.) Conviene no olvidarlo. (Rumores.)

El señor PRESIDENTE: Silencio, por favor.

El señor VICEPRESIDENTE PRIMERO DEL GOBIERNO Y MINISTRO DEL INTERIOR (Pérez Rubalcaba): Y el Supremo les dio un revolcón. Lea usted su sentencia. El Supremo lo que dice es que son conjeturas que derivan de que el señor Chaves era entonces presidente de la Junta de Andalucía. En roman paladino: insidias contra el presidente de la Junta de Andalucía, un revolcón.(Rumores.) Esa es la realidad y vamos al fondo, señor Tarno. Vamos al fondo de la cuestión porque el fondo es ese, el fondo son insidias. Y le voy a decir más: insidias y, ¿sabe qué? Muchísimo rencor. Insidias y rencor, no contra el vicepresidente del Gobierno, que también, sino contra quien fue durante muchos años presidente de la Junta de Andalucía, por cierto, porque así lo quisieron los andaluces. Muchas gracias, señor presidente. (Aplausos.-Una señora diputada: ¡Muy bien!) (DSCD 219, 26-1-2011, 11)

Como vemos, las evaluaciones actúan como un argumento falaz, pero son muy frecuentes en el discurso político. Acusación directa, incluso insultos, encontramos en:

(36) El señor VICEPRESIDENTE TERCERO DEL GOBIERNO Y MINISTRO DE POLÍTICA TERRITORIAL Y ADMINISTRACIÓN PÚBLICA (Chaves González): Gracias, señor presidente.

Señor Moreno, a mí me sorprende que esta pregunta se pueda formular en esta Cámara, porque usted no formula una pregunta, usted me acusa de la comisión de un delito al amparo de la inviolabilidad que le proporciona esta Cámara. (Aplausos.) Por lo tanto, señor Moreno, si usted tiene un mínimo de dignidad y de responsabilidad, nada más terminar este debate lo que debe hacer es irse al juzgado y poner una demanda (Aplausos.-Varios señores diputados: Ahí, ahí.) Y si no lo hace...

El señor PRESIDENTE: Silencio.

El señor VICEPRESIDENTE TERCERO DEL GOBIERNO Y MINISTRO DE POLÍTICA TERRITORIAL Y ADMINISTRACIÓN PÚBLICA (Chaves González): ...quedará demostrado una vez más, señor Moreno, que usted es un mentiroso, un calumniador y un difamador. (Varios señores diputados: ¡Muy bien!- Aplausos.) (Diario de Sesiones del Parlamento Español 241, 45-2011, p.11)

Se acompaña de un mandato o recomendación, que en sí parece una forma más atenuada (lo que debe hacer) pero que se intensifica al ir seguido de las consecuencias de su actuación: Y si no lo hace quedará demostrado una vez más, señor Moreno, que usted es un mentiroso, un calumniador y un difamador. El insulto aparece como consecuencia de los hechos, y, por tanto, como algo demostrado y no derivado de la propia emoción o subjetividad del vicepresidente. Asimismo, la condicional si usted tiene un mínimo de dignidad $y$ de responsabilidad provoca una inferencia clara acusadora, pero el medio lingüístico es claramente indirecto (Brown-Levinson 1987) y atenuador.

Las mismas acusaciones directas encontramos en: 
(37) El señor GIL LAZARO: Se le ha acabado ya el tiempo de las mentiras, señor vicepresidente. El pueblo español ha dicho en las urnas que esta harto de un Gobierno inútil que le ha engañado a destajo. (Rumores.)

El señor PRESIDENTE: Silencio.

El señor GIL LAZARO: Diga usted lo que diga, por mucho que trate de negar la evidencia, ahora queda demostrado también con ese informe policial que en el caso Faisán usted ha mentido de forma burda, insolente y reiterada.(DSCD 247, 25-5-2011, p.9)

En conclusión, el texto político emplea la subjetividad como medio de argumentación, ya sea atacando al otro, minusvalorándolo, insultando, destruyendo directamente su imagen, evaluando los actos del otro, usando expresiones emotivas, lanzando la carga de la emoción sobre el contrincante, incluso utilizándola como arma: emplear lo positivo con un fin negativo. Son, por tanto, argumentaciones mal construidas, falacias o paralogismos (Woods-Irvine-Walton 2004, Woods-Walton 1989, van Eemeren-Garssen-Meuffels 2009), pero de una gran rentabilidad práctica y que actúan con una carga descortés.

\section{Emoción para la persuasión: el texto publicitario}

Otro tipo textual donde se emplean argumentativamente las emociones es la publicidad $^{35}$. Recurrir a los sentimientos del receptor es fundamental para conseguir el éxito en la argumentación ${ }^{36}$. Podemos verlo en el reciente anuncio de Danacol, que protagoniza Manolo Escobar ${ }^{37}$.

(38) ME: ¿Mi hija? Lo mejor de mi vida Hija: ¿Mi padre? Un corazón inmenso

ME: ¿Un momento bueno? Cuando le cantaba para dormirla

Hija: ¿Uno malo? Cuando no cuidó su corazón

\footnotetext{
${ }^{35}$ Cfr., entre otros, Kerbrat-Orecchioni (1998), Lo Cascio (1998), Adam-Bonhomme (2000), FuentesAlcaide (2002), Garrido (1996), González Camino (2008).

${ }^{36}$ No en vano el fin de la argumentación es, como sostienen Perelman-Olbretchs-Tyteca $(1989,34)$ en la introducción de su obra: "provocar o aumentar la adhesión de las personas a las tesis presentadas para su asentimiento" (en cursiva en el original). Van Dijk (2000a, 57-8) las califica claramente como falacias: "Fallacies, very generally defined, are breaches of argumentation rules and principles. (....) And argumentation rules are broken if, for instance, we use an irrelevant argument, play on people's emotions, ask the opponent to show I am wrong, argue that something must be true because everybody thinks so, or because some authority says so".

${ }^{37}$ Puede verse en el siguiente enlace: http://www.youtube.com/watch?v=Wu4eGxxyb94 Consulta 8-52011.
} 
ME: Fue culpa del colesterol

Hija: Tenía que reducirlo... y la dieta no fue suficiente

ME: Aprendí que con el colesterol no se juega

Voz en off: el exceso de colesterol es una causa de riesgo en el desarrollo de enfermedades del corazón

Danacol reduce la absorción de colesterol ayudando a expulsarlo

ME: No quiero equivocarme más. Por eso es siempre Danacol

Hija: Ahora vivo más tranquila. Sé que se cuida

Voz en off: Danacol es el más recomendado para reducir el colesterol

Hija: Ojalá lo tomaran todos los padres con colesterol.

Se utilizan los sentimientos de una familia, el sufrimiento familiar, para convencer. Es algo consciente, como podemos deducir de las propias declaraciones de la empresa de marketing:

"Según Alessio Sarina, responsable de marketing de Danacol, "hemos escogido a Manolo Escobar porque representa a todas aquellas personas que se preocupan por mantener un buen estado de salud y que se han dado cuenta de la importancia de cuidar su colesterol. Él ha vivido en su propia piel que, adoptando ciertas medidas, uno puede conseguir mantenerse sano y sentirse bien". (http://www.marketingnews.es/gran-consumo/noticia/1046517028005/danacolelige-manolo-escobar-comunicar.1.html, última consulta 8/2/2011).

La publicidad intenta conectar con los sentimientos del usuario para anunciar el producto. Se invocan sentimientos positivos generalmente, como el placer o el disfrute:

(39) ¡Disfruta de tu seguro desde el primer día! (Seguros Lifeline)

O se utiliza la expresión emotiva de alegría, un enunciado exclamativo para reclamar la atención sobre el producto y contagiar al receptor ese sentimiento positivo:

(40) ¡A Ahora más que nunca, quitamos el 18\% de IVA a todos nuestros productos! (Media Markt, 20 minutos, 31-1-2011)

Otras veces se dirige hacia los deseos de los hablantes de ser aceptados socialmente, hacia su autoestima ${ }^{38}$. El eslogan de la empresa Media Markt (dedicada a la venta de electrodomésticos y productos de telefonía, informática, audio y video) empatiza con un sentimiento común en toda la sociedad: el miedo a ser catalogado como tonto. Todos queremos ser listos. Huimos de la vergüenza de ser considerados tontos. Por ello recurre a la primera persona, mucho más directa y cortés:

(41) Media Mark. Yo no soy tonto.

En la publicidad institucional, el poder recurre también a todos estos mecanismos. En algunas campañas de la DGT ${ }^{39}$ ("No podemos conducir por ti”, por ejemplo) se recogen

\footnotetext{
${ }^{38}$ Se situaría en el sistema de la apreciación, dentro de la evaluación actitudinal. Vid. Martin-White (2005), o Kaplan (2004).

${ }^{39}$ Cfr. Díaz Domínguez (2010a).
} 
todos los posibles argumentos que podría utilizar un ciudadano, independientemente de su valoración o justificación ética. Se reproducen para crear empatía con él, recoger su voz y aceptar sus puntos de vista. Entre ellos se recurre a argumentos muy sensibles, que apelan a los sentimientos, para conseguir un cambio en la conducta:

(42) Porque odias que te vean llorar

Porque tu hijo necesita un padre

Por conocer a tus nietos

Porque odias las agujas...

Para que tu madre no tenga que ir con flores al Km. 23 de alguna carretera

Porque no quieres matar a tu chica

Porque los cementerios son fríos

Porque vas a matar a tus colegas. A tu chica. A los hijos que aún no has tenido. Y no vas a poder seguir viviendo como si nada.

Verbos como odias, necesitas, o la frecuente referencia al receptor con un trato de cercanía (tu hijo, tus nietos, tu madre, tu chica, tus colegas) son sus manifestaciones lingüísticas más visibles. Incluso se llega a un extremo más drástico, excesivamente visual, rozando lo desagradable:

(43) Para no partirte el cráneo contra el asfalto.

Porque un bebé en brazos es lo primero que sale disparado ${ }^{40}$

En estos casos se intenta provocar una emoción fuerte en el receptor, a través de la referencia de las acciones evocadas. Mezcla conscientemente argumentos lógicos con otros falaces. Busca conseguir con ello emociones de rechazo: convencer por el miedo a las consecuencias negativas. Nos crea una emoción para que reaccionemos, aunque sea negativa, pero su eficacia y el fin perseguido, proteger nuestra vida, justifica la elección de estos medios. Podemos verlo en el ejemplo 44, perteneciente a un "tótem" dirigido a los jóvenes, y en el 45, cartel de la campaña general.

\footnotetext{
${ }^{40}$ Para un análisis más pormenorizado ver Díaz Domínguez (2010a y b).
} 
(44)

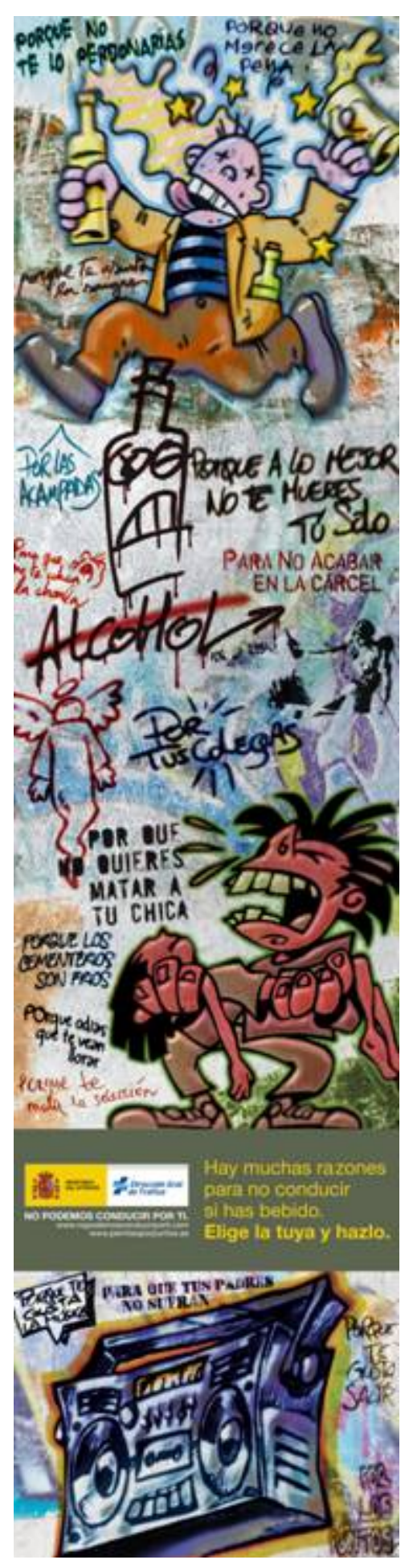

(http://www.dgt.es/was6/portal/contenidos/visor_multimedia/\#, última consulta 9/2/2011) 
(45)

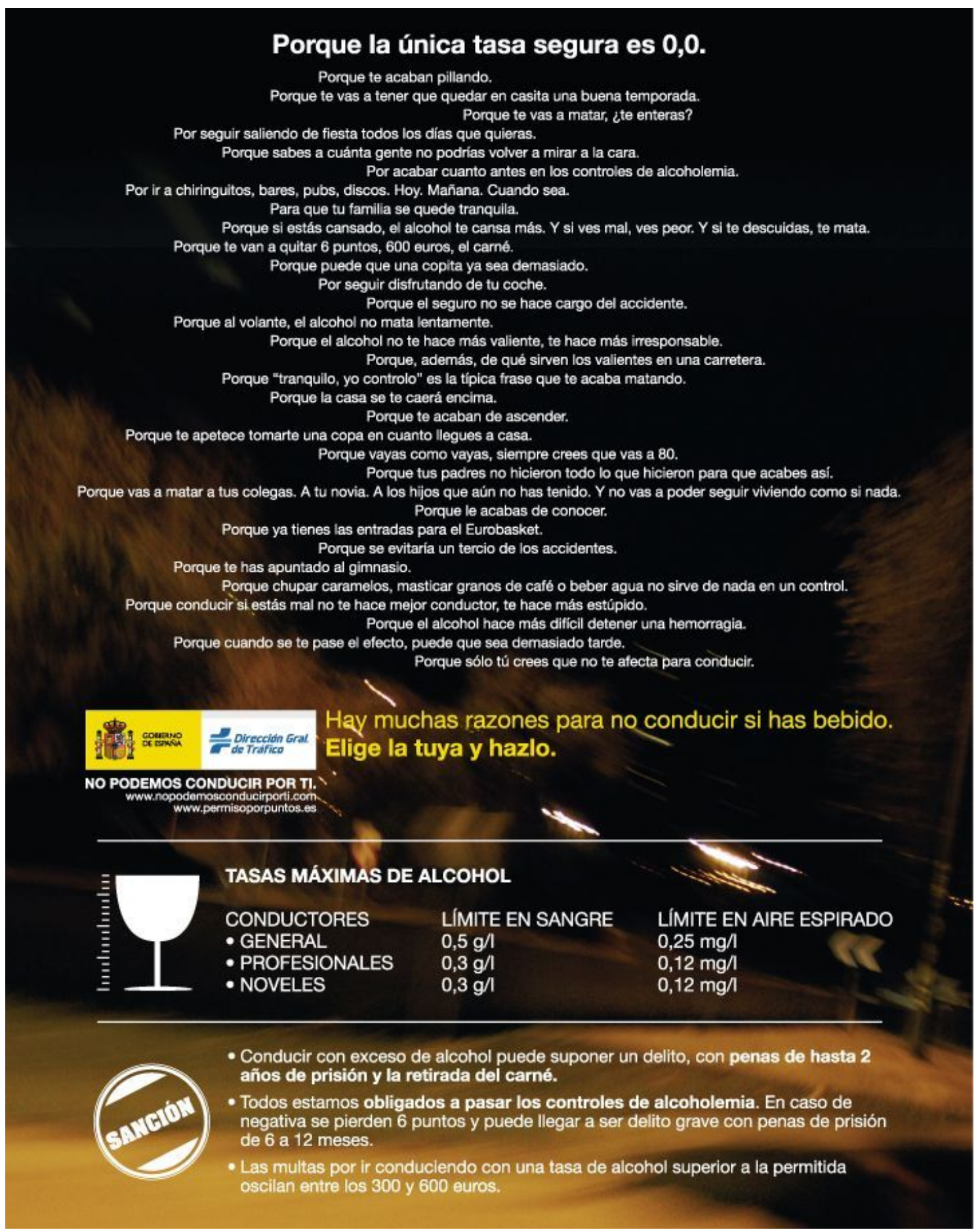

(http://www.dgt.es/was6/portal/contenidos/visor_multimedia/\#app=7f51\&c92c-selectedIndex=0 última consulta $8 / 2 / 2011$ ) 
En una campaña del Ministerio de Igualdad, No a la explotación sexual, se recurre a la expresión de sentimientos (empatía, arrepentimiento, pena o lástima por la persona que está siendo usada...) para condenar una conducta. Se utiliza la imagen del usuario que recurre a estos servicios, a quien se presenta en una actitud positiva, con sentimientos de remordimiento y con el propósito de modificar su comportamiento. La imagen creada no es de condena, ya que pretende convencer al receptor de la campaña a través de la reflexión. Incluso se le da la palabra a él, al presunto "culpable", que muestra su arrepentimiento. La imagen elegida es presentar la postura correcta, la solución al problema, provocando, a la vez, sentimientos de lástima y de respeto hacia la víctima. Toda la campaña está montada en torno a la exposición de sentimientos de los representantes masculinos, pero desde la situación de futuro deseada: la eliminación de estas conductas. El Ministerio quiere llegar al ciudadano que practica estos comportamientos de forma amable, y le proporciona los argumentos para cambiar. No se impone. Ambas imágenes, la del Gobierno y la del propio ciudadano, quedan salvadas con ello.

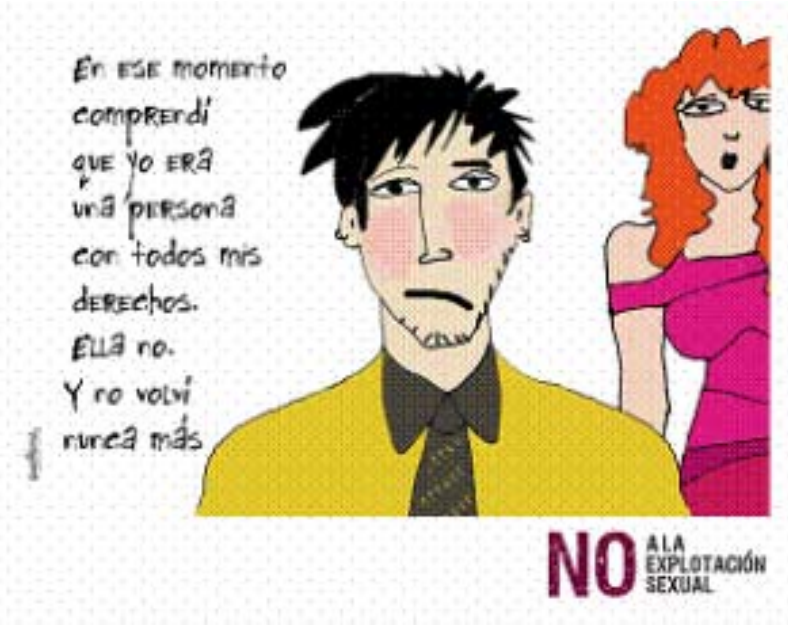



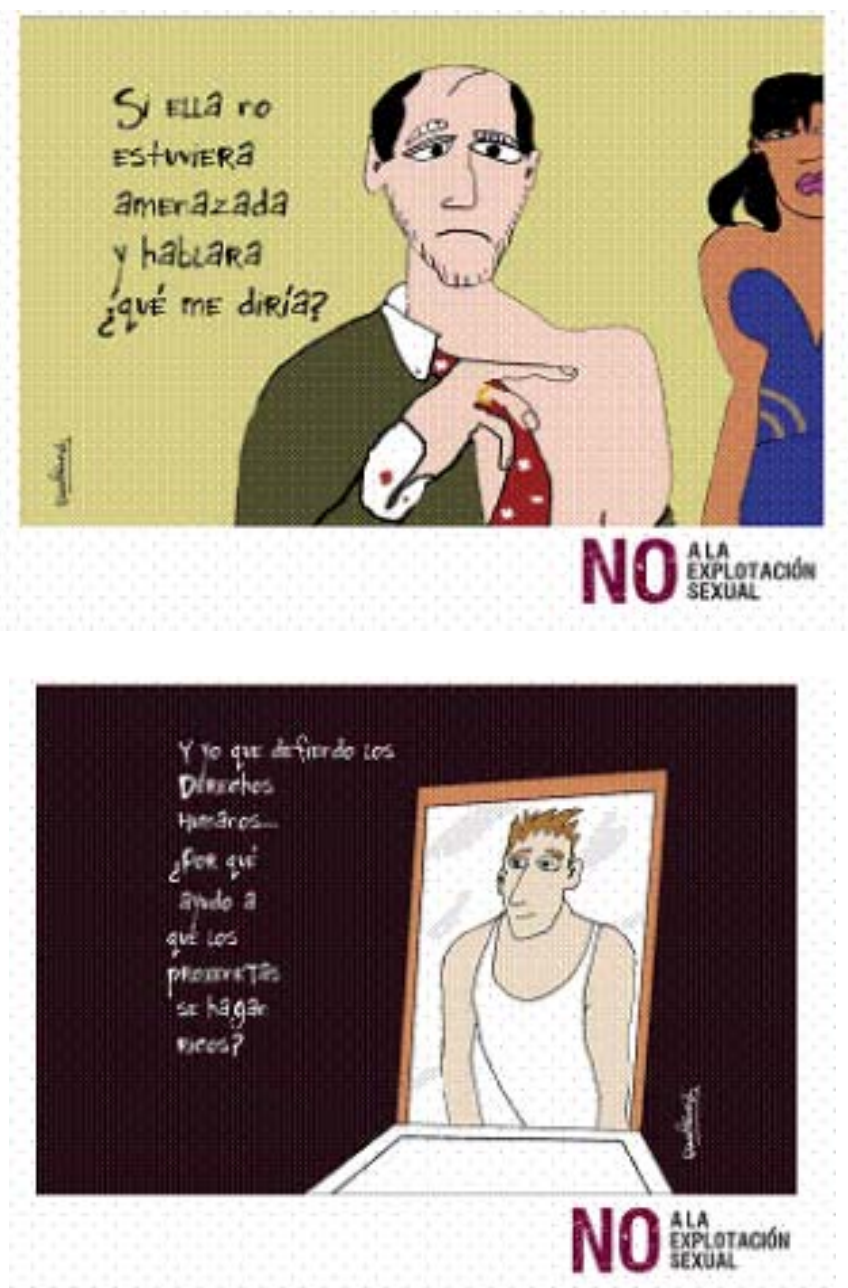

(http://www.migualdad.es/ss/Satellite?c=MIGU_Campania_FA\&cid=1244647349000\&pageid=1193049 831625\&pagename=MinisterioIgualdad\%2FMIGU_Campania_FA\%2FMIGU_campaniaGenerica, y en http://www.encontraportada.com/2010/01/no-a-la-explotacion-sexual-posavasos-para-concienciar-contrala-trata-de-seres-humanos/, última consulta 8/2/2011)

En la primera diapositiva el personaje acude a una narración (en ese momento comprendí...) y empatiza con el receptor a través de la alusión a los derechos humanos, y a su condición de persona. En la segunda establece un diálogo con el lector o un diálogo interiorizado, que actúa como mecanismo indirecto (si ella..., ¿qué me diria?). En la tercera la autorreflexión ante el espejo (imagen visual) establece la contraposición de argumentos: defender los derechos humanos/ ayudar a que los proxeneteas se hagan ricos (Y yo que defiendo...). 
La polarización de las acciones es clara y el dibujo de la realidad de la víctima también: persona sin derechos, amenazada, sometida a la esclavitud. El contenido semántico de los términos elegidos y los topoi convocados ayudan a conseguir una mayor eficacia en la argumentación, pero también tienen un efecto más allá de ella y del comportamiento cortés con el ciudadano receptor de la campaña. Actúa también como una operación de autoimagen del propio poder, que se presenta como cercano al ciudadano. La cortesía tiene, pues, una intención claramente estratégica dirigida no solo hacia el mensaje, sino también hacia los emisores del mismo.

En otros mensajes se recurre a los mismos mecanismos (la polifonía, entre ellos) pero en dirección contraria, ya que el contexto social justifica un tono más impositivo. Podemos verlo en la siguiente campaña de prevención del maltrato doméstico que ha llenado la red, nuestras vallas publicitarias y paredes. Para concienciar del drama que esto supone, se exponen los sentimientos de los implicados en el hecho, seguido del eslogan. Se le da la palabra a cada uno de ellos: la mujer: No se te ocurra ponerme la mano encima JAMÁS, dirigida al maltratador. El hijo: Mamá, hazlo por nosotros. $A C T U ́ A$, intentando conseguir una actitud de denuncia por parte de la mujer. La imagen del hombre es utilizada para representar no al supuesto maltratador, sino a otra persona de su sexo, encarnando el rechazo del propio colectivo masculino: Cuando maltratas a una mujer dejas de ser un hombre. De este modo se ataca la propia identidad de rol del maltratador, se muestra la aversión de la sociedad en su conjunto y se destierran viejos estereotipos o costumbres malsanas.

La polifonía es el mecanismo lingüístico empleado para exponer el rechazo y conseguir que el receptor del mensaje cambie su conducta. Pero ahora se recurre a emociones negativas que van dirigidas claramente contra el maltratador: la crítica (hombre), la autodefensa mediante la imposición (mujer) y el ruego (hijo). Estos son los argumentos empleados para conseguir el fin: no maltrates, conclusión no dicha, pero suficientemente clara, y expuesta a través de fórmulas lingüísticas directas: no se te ocurra, hazlo, actúa, potenciadas por marcadores de fuerza como jamás en el segundo mensaje. 
(47) Contra el maltrato
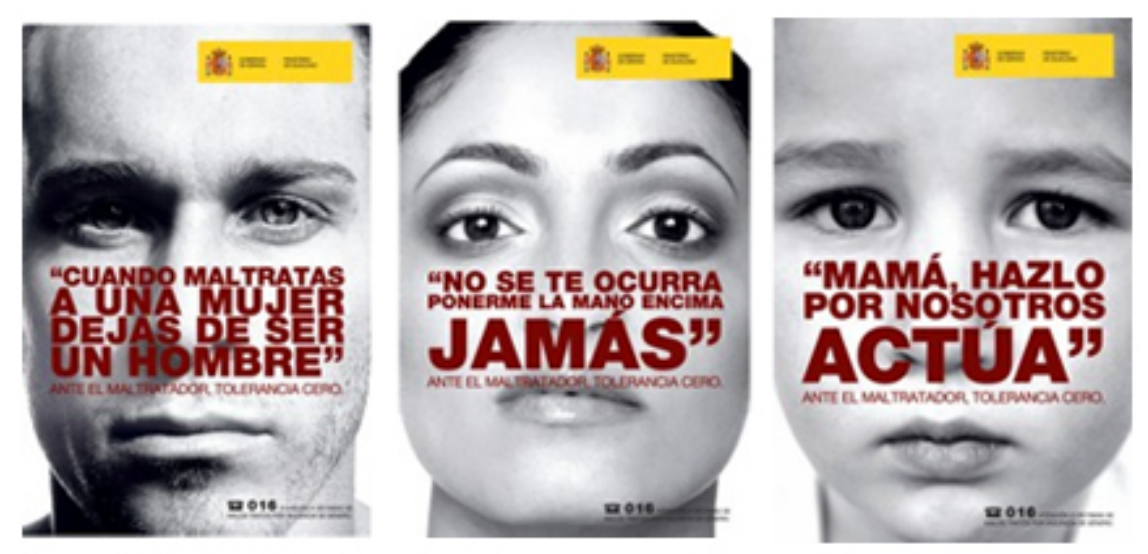

(http://www.inmujer.es/ss/Satellite?c=MIGU_Campania_FA\&cid=1193049832542\&pageid=1193049831 625\&pagename=MinisterioIgualdad\%2FMIGU_Campania_FA\%2FMIGU_campaniaGenerica, última consulta 19/4/2012)

\section{Conclusiones}

En este trabajo hemos querido exponer cómo la subjetividad está presente en los mensajes públicos y privados. Su inserción en el discurso se realiza a través de dos vías:

a) la conversión en elemento lingüístico que modula nuestros mensajes y expresa la relación con el yo hablante (modalidad)

b) el uso de la emoción en la relación interactiva, en el plano interpersonal. Además, en un segundo momento tanto unos como otros se emplean como mecanismos para la argumentación y la cortesía. Lo subjetivo salta, pues, a la macroestructura de varias formas:

-La modalidad lingüística se emplea como un mecanismo de refuerzo o atenuación de la (des)cortesía

-La subjetividad es un medio de asegurar la afiliación en la interacción 
-Las emociones son utilizadas como argumento falaz: ya sea el ataque directo al otro mediante la acusación o minusvaloración (argumento ad hominem), o el uso de las emociones, para provocar sentimientos negativos en el receptor (enfado, molestia...), o convencerlo apelando a la lástima, la pena, los sentimientos de alegría, disfrute, etc.

Este mecanismo es altamente rentable, de ahí la extensión de su uso en tipos discursivos que buscan la mayor eficacia comunicativa, como la publicidad y el discurso político, sin olvidar, claro está, la conversación cotidiana, donde está omnipresente. De esta manera, el hablante hace material lingüístico lo que pertenece al plano emotivo y lo usa en provecho propio para conseguir sus fines comunicativos. La rentabilidad es evidente, aunque también cabe plantearse si recurrir al pathos es ético, asunto este que queda para otro trabajo.

Bibliografía

AdAm, J.M.-Bonhomme, M. (2000): La argumentación publicitaria, Madrid, Cátedra.

AlCAIDE DE LARA, E. R. (1999): «Las intervenciones parlamentarias, ¿lengua hablada o lengua escrita?», Anuario de Estudios Filológicos, 22, págs. 9-36.

Alvar, M. (coord. 1997): El lenguaje político, Madrid, Fundación F. Ebert.

Anscombre, J.C.- Ducrot, O. (1983): L'argumentation dans la langue. Lieja, Pierre Mardaga.

Arce Castillo, Á (2006): El lenguaje político. Recursos pragmático-discursivos en registros formales e informales, Salamanca, Ratio Legis.

ARNDT, H. - R.W. JANNEY (1991): "Verbal, prosodic, and kinesic emotive contrasts in speech", Journal of Pragmatics 15, págs. 52 1-549.

BAJTIN, M. (1982): Estética de la creación verbal, México, Siglo XXI.

BALly, C. (1965[1944]): Linguistique générale et linguistique française, Berna, Francke, $4^{\mathrm{a}}$ ed.

BAMBERG, M. (1997): "Language, concepts and emotions: the role of language in the construction of emotions", Language Sciences, 19, 4, págs. 309-340. 
Bayley, P. (ed. 2004): Cross-Cultural Perspectives on Parliamentary Discourse, Filadelfia, J.Benjamins P.C.

BeSniER, N.(1990): “Language and affect”, Annual Review of Anthropology 19, págs. 419-451.

Biber, D.-E. Finegan (1989): "Styles of stance in English: Lexical and grammatical marking of evidentiality and affect". En E. Ochs (ed.): The pragmatics of affect. A special issue of Text, Berlin/Nueva York, Mouton de Gruyter, págs. 93-124.

Blas Arroyo, J. L. (2003): "Perdóneme que se lo diga, pero vuelve usted a faltar a la verdad, señor González": form and function of politic verbal behaviour in face-toface Spanish political debates", Discourse \& Society, 14(4), págs. 395-424.

Blas Arroyo, J.L. (2000): ““"Mire usted Sr. González”. Personal deixis in Spanish political-electoral debate", Journal of Pragmatics, 32 (1), págs. 1-28.

Blas ARroyo, J.L. (2009): "La descortesía verbal en contextos institucionales: entre la realidad y el espectáculo”. En C.Fuentes-E.Alcaide (eds. 2009), págs. 78-97.

Blas Arroyo, J.L. (2011): Políticos en conflicto: una aproximación pragmáticodiscursiva al debate electoral cara a cara, Berna, Peter Lang.

Bolívar, A. (1997): "La negociación de la evaluación en editoriales de periódicos", Boletín de Filología Tomo XXXVI, págs. 7-24.

Bolívar, A. (2001): “The negotiation of evaluation in written text". En M. Scott y G. Thompson (eds.): Patterns of Text: In honour of Michael Hoey, Ámsterdam, John Benjamins, págs. 129-158.

BolíVAR, A. (2006): "La función de la evaluación en artículos y ensayos humanísticos".

En J. Falk, J. Gille y F. Bermúdez Wachtmeister (Coords.): Discurso, interacción e identidad, Estocolmo, Universidad de Estocolmo, págs. 109-136.

BorTHWiCK, R.L. (1993): “On the floor of the house”. En M.Franklin-P.Norton (eds.), págs.73-103.

BOUSFIELD, D. - M.LoCHER (2008): Impoliteness in language: studies on its interplay with power in theory and practice, Berlín, Mouton the Gruyter.

BRAVO, D. (2001): "Sobre la cortesía lingüística, estratégica y conversacional en español”, Oralia, 4, págs. 299-314.

BRAVO, D. (2004): “Tensión entre universalidad y relatividad en las teorías de la cortesía”. En Bravo, D. - Briz, A. (eds., 2004), págs. 15-37. 
Bravo, D.- A.Briz (eds. 2004): Pragmática sociocultural: estudios sobre el discurso de cortesía en español, Barcelona, Ariel.

Bravo, D.(ed. 2005). Estudios de la (des)cortesía en español. Categorías conceptuales y aplicaciones a corpora orales y escritos, Buenos Aires, Editorial Dunken.

BRIZ, A. - GRUPO VAL.Es.Co. (2002): Corpus de conversaciones coloquiales, Madrid, Arco Libros.

BRIZ, A. (2004): “Cortesía verbal codificada y cortesía verbal interpretada en la conversación". En Bravo, D. - Briz, A. (eds., 2004), 67-94.

Brown, P.- Levinson, S. C. ([1978]1987): Politeness. Some Universals in Language Use, Cambridge, Cambridge University Press.

CAFFI, C.-R.W.JANNEY (1994): “Toward a pragmatics of emotive communication", Journal of Pragmatics 22, 325-373.

ChAFE, W. L. (1982): "Integration and involvement in speaking, writing, and oral literature". En D. Tannen (ed.): Spoken and written language: Exploring orality and literacy. Norwood, NJ, Ablex, págs. 35-53.

Charaudeau, P. (2008): "Pathos et discours politique”. En Rinn M. (coord.): Émotions et discours. L'usage des passions dans la langue, Rennes, Presses universitaires de Rennes, http://www.patrick-charaudeau.com/IMG/pdf/2008_Pathos_Actes_Brest_pdf, consulta 1-4-2012.

Chilton, P. (2004): Analysing Political Discourse, Londres, Routledge.

Chilton, P., (ed. 2002): Politics as text and talk. Analytic approaches to political discourse, Filadelfia, J.Benjamins.

CUlPEPER, J. (1996): “Towards an anatomy of impoliteness", Journal of Pragmatics 25 (3), págs. 349-367.

DAVID, J. ET KLEIBER, G. (dir.) (1983) : La notion sémantico-logique de modalité, París, Klincksieck.

DíAz Domínguez, M.L. (2010a): “Argumentación y manejo de la imagen en publicidad institucional. La DGT”. Discurso y Sociedad, 4,4, págs. 87-115.

DíAz Domínguez, M.L. (2010b): Argumentación y cortesía en publicidad institucional. Análisis Lingüistico Pragmático de Campañas de la DGT, trabajo de investigación manuscrito. 
Ducrot, O. (1995): “Les Modificateurs Déréalisants”, Journal of Pragmatics, 24, págs. 145-165.

EgGINS, S. (1994/2004): An Introduction to Systemic Functional Linguistics, Londres, Pinter.

ENGLEBRETSON, R. (eds. 2007): Stancetaking in discourse, Ámsterdam/ Filadelfia, J.Benjamins.

ENIS, R.H. (2006): “Probably”. En Hitchcock, D.-B. Verheij (eds.), cap. 10. 145-164

FAIRCLOUGH, N. (1988): "Register, power and socio-semantic change". En D. Birch M. O’Toole (eds.): Functions of style, Londres, Pinter, págs. 111-125.

FERNÁNDEZ LAGUNILLA, M. (1980): “Lexicología y política: un campo léxico dentro del vocabulario republicano (1876-1899)", Verba 7, págs. 379-387.

FERnÁNDEZ LaguniLla, M. (1999): La lengua en la comunicación política I y II, Madrid, Arco Libros.

FINEGAN, E.(1995): "Subjectivity and subjectivisation: an introduction". En D.SteinS.Wright (eds.) págs. 16-30.

Franklin, M.-P. Norton (eds. 1993): Parliamentary Questions, Oxford, Oxford University Press.

Fuentes RodRíGuez, C. (1991a): “Algunas reflexiones sobre el concepto de modalidad”, Revista de la Sociedad Española de Lingüistica Aplicada 7, págs. 93-108.

Fuentes Rodríguez, C. (1991b): “Adverbios de modalidad”, Verba 18, págs. 275-321.

FUENTES RodRÍGUez, C. (2000): Lingüistica pragmática y análisis del discurso, Madrid, Arco Libros.

Fuentes RodRíguez, C. (2003): "Operador/conector: un criterio para la sintaxis discursiva", Rilce 19,1, págs. 61-85.

FuENTES RodRÍGUEZ, C. (2009a): "La argumentación en la lengua y la cortesía verbal, ¿dos teorías distintas?”, XIII Jornadas de Lingüística, M.Casas-R.Márquez (eds.), Publicac. Univ. Cádiz, 109-148.

FueNTES RodríGuez, C. (2009b): Diccionario de conectores y operadores del español, Madrid, Arco Libros.

Fuentes RodríGuez, C. (2009c): "Parliamentary (im)politeness and argumentative force: “decirles, señorías, que...(to say, sirs, to you, that...)". En G. Álvarez Benito, G. Fernández Díaz- I. Iñigo (eds.): Actas del I Congreso Internacional de 
Estrategias del Discurso Político /Proceedings of the I International Conference on Political Discourse Strategies. Sevilla: Mergablum, págs. 63-80.

Fuentes RodrígueZ, C. (2009d): "El debate entre Zapatero y Rajoy: ¿convencer a quién? Estudio textual e interactivo". Tonos Digital, 18, www.tonosdigital.com

Fuentes RodríGuez, C. (2010a): La gramática de la cortesía en español/LE, Madrid, Arco Libros.

Fuentes RodrígueZ, C. (2010b): "La aserción parlamentaria: de la modalidad al metadiscurso", Oralia, 13, págs. 97-125.

Fuentes RodRíGueZ, C. (2011a): “(Des)cortesía y violencia verbal: implicaciones lingüísticas y sociales”. En C.Fuentes-E.Alcaide-.E.Brenes (eds, 2011), págs. 2774.

Fuentes RodríGueZ, C. (2011b): "El debate entre Zapatero y Rajoy: estudio Argumentativo", Tonos digital 20, www.tonosdigital.com

Fuentes RodríGUEZ, C. (2011c): "Las preguntas orales en el parlamento español”. Philologia Hispalensis, en prensa.

Fuentes Rodríguez, C. (2011d): “Cortesía e imagen en las "preguntas orales” del Parlamento español”. Cultura, lenguaje y representación, 9, págs. 53 - 79.

FueNTES RodRÍGUEZ,C. (2012): "Las preguntas de control al gobierno en el Parlamento Andaluz: solidaridad y confrontación”, en prensa.

Fuentes Rodríguez, C. - E. AlCAide LARA (1996): La expresión de la modalidad en el habla de Sevilla, Publicaciones del Excmo. Ayuntamiento de Sevilla, 1996.

Fuentes Rodríguez, C. - E. Alcaide LARa (2002): Mecanismos lingüisticos de la persuasión. Madrid, Arco Libros.

Fuentes RodríGuez,C.-E. AlCAIDE LARA (2008): (Des)cortesía, agresividad y violencia verbal en la sociedad actual, Sevilla, Publicaciones Universidad Internacional de Andalucía.

Fuentes Rodríguez, C. - E. Alcaide Lara (eds., 2009): Manifestaciones textuales de la (des)cortesía y agresividad verbal en diversos ámbitos comunicativos, Sevilla, Publicaciones Universidad Internacional de Andalucía.

Fuentes Rodríguez, C. -E.AlCAide- E.Brenes (2011, eds.): Aproximaciones a la (des)cortesía verbal en español, Berna, Peter Lang. 
GARRIDO, J. (1996, coord.): La lengua y los medios de comunicación, Madrid, Universidad Complutense.

GOFFMAn, E. (1959): The presentation of self in everyday life, Nueva York, Doubleday. GOFFMANN, E. (1967): Interaction ritual. Essays on face-to-face behaviour, Nueva York, Doubleday.

GonzÁlez CAMinO, G. (2008): "Eslóganes y cortesía: diferencias en la gestión interpersonal de la imagen social entre la publicidad televisiva emocionalsensorial y la racional". Actas del III. Coloquio Internacional del programa EDICE, Valencia, Universidad de Valencia, págs. 556-585.

GONZÁLEZ RodRíGUEZ, M.J. (2011): “La expresión lingüística de la actitud en el género de opinión: el modelo de la valoración", RLA, Revista de Lingüistica Teórica y Aplicada, 49 (1), págs. 109-141.

GUMPERZ, J. J.(1977): “Sociocultural knowledge in conversational inference". En M. Saville-Troike, ed., Georgetown University Round Table on Languages and Linguistics, Washington, DC: Georgetown University Press, págs.191-212.

HALLIDAY, M.A.K. (1973): Explorations in the Functions of Language, Londres, Edward Arnold.

M. A. K. (1979): 'Modes of meaning and modes of expression: types of grammatical structure, and their determination by different semantic functions'. En D. J. Allerton, E. Carney \& D. Holdcroft (eds), Function and Context in Linguistic Analysis: Essays Offers to William Haas. Cambridge, Cambridge University Press, 57-79.

Halliday, M. A. K. (1994, 2004): An Introduction to Functional Grammar. Londres: Edward Arnold. (2004, $3^{\mathrm{a}}$ ed., revisada por C. M. I. M. Matthiessen).

HARRIS, S. (1991): "Evasive action: how politicians respond to questions in political interviews”. En P.Scannell (ed.): Broadcast Talk, Londres, Sage, págs. 76-99.

HARRIS, S. (2001): "Being politically impolite: extending politeness theory to adversarial political discourse", Discourse and Society 12 (4), págs. 451-472.

HAVERKATE, H. (1984): Spanish Acts, Speakers and Hearers. Reference and Referential Strategies in Spanish, Ámsterdam, Benjamins.

HAverkate, H. (1987): "La cortesía como estrategia conversacional”, Diálogos Hispánicos de Ámsterdam, 6, págs. 27-63. 
Haverkate, H. (1994): La Cortesía Verbal. Estudio Pragmalingüístico, Madrid, Gredos.

Hernando CuAdrado, L. A. (2004): “Tendencias actuales del español en el discurso político”. En I. Sanz Sainz -Á.Felices Lago (eds): Las nuevas tendencias de las lenguas de especialidad en un contexto internacional y multicultural, Current trends of languages for specific purposes in an internacional and multicultural context, Granada, págs. 121-129.

HitchCOCK, D.- B. VerHeIJ (eds., 2006): Arguing on the Toulmin model. New essays in Argument analysis and Evaluation, Dordrecht, Springer.

HÜBLER, A. (1987): “Communication and expressivity”. En R. Dirven - V. Fried (eds.): Functionalism in linguistics, Ámsterdam/ Filadelfia: Benjamins, págs. 357-380.

Hunston, S. - G. ThOMPson (eds), 2000. Evaluation in Text: Authorial Stance and the Construction of Discourse, Oxford, Oxford University Press.

HYMES, D. (1972): "Models of the interaction of language and social life". En J. Gumperz and D. Hymes (eds.): The ethnography of communication, Nueva York, Halt, Rinehart and Winston, págs. 35-71.

ILIE, C. (2001): "Unparliamentary Language: Insults as Cognitive Forms of Ideological Confrontation". En R. Dirven, R.Frank and C. Ilie (eds.): Language and ideology. Volume II: Descriptive cognitive approaches. Ámsterdam / Filadelfia, John Benjamins, págs. 235-262.

ILIE, C. (2003a): "Discourse and metadiscourse in parliamentary debates", Journal of Language and Politics, 2 (1), págs.71-92.

ILIE, C. (2003b): "Histrionic and agonistic features of parliamentary Discourse", Studies in Communication Sciences, 3 (1), págs. 25-53.

ILIE, C. (2004): "Insulting as (un)parliamentary practice in the British and Swedish parliaments: A rhetorical approach". En P. Bayley (ed.), págs. 45-86.

IRVINE, J. T. (1982): "Language and affect: Some cross-cultural issues". En H. Bymes (ed.): Contemporary perceptions of language: Interdisciplinary dimensions, Washington, DC, Georgetown University Press, págs. 31-47.

ISIK-GÜLER, H.- S. RUHI (2010): "Face and impoliteness at the intersection with emotions: A corpus-based study in Turkish”, Intercultural Pragmatics 7-4, págs. $625-66$. 
KAPLAN, N. (2004): "Nuevos desarrollos en el estudio de la evaluación en el lenguaje: la teoría de la valoración", Boletín de Lingüistica, 22, págs. 52-78

KARKKaInen, E. (2003): Epistemic Stance in English Conversation, Ámsterdam / Filadelfia, J. Benjamins.

KATRIEL, T.- M. DASCAL (1989): “Speaker's commitment and involvement in discourse". En Y. Tobin (ed.): From sign to text, Ámsterdam/ Filadelfia, Benjamins, págs. 275-295.

Kaul De Marlangeon, S. (1992) (1995-2003): La fuerza de la cortesía-descortesía y sus estrategias en el discurso tanguero de la década del 20. Tesis de Especialista en Lingüística en la Universidad Nacional de Córdoba, Argentina, aprobada en 1992. Publicada posteriormente En RASAL (Revista de la Sociedad Argentina de Lingüística) 3, SAL-UNT, Tucumán, 1995, pp. 7-38, y en formato electrónico en 2003: http://edice.org/Documentos/SKaul.pdf.

Kerbrat-Orecchioni, C. (1986): La enunciación. De la subjetividad en el lenguaje. Buenos Aires, Hachette.

KERBRAT-ORECCHIONI, C. (1998): “La argumentación en la publicidad”, Escritos, 1718, págs. 291-326.

KiEnPoInTnER, M. (1997): "Varieties of rudeness. Types and functions of impolite utterances", Functions of Language, 4 (2), págs. 251-287.

KiENPOINTNER, M. (2008a): "Impoliteness and emotional arguments", Journal of Politeness Research 4, págs. 243-265.

KienPoInTner, M. (2008b): “Cortesía, emociones y argumentación”, Actas del III. Coloquio Internacional del programa EDICE, Valencia, Universidad de Valencia, págs. 22-26.

Kovacci, O. (1986): Estudios de gramática española. Buenos Aires, Hachette, S. A.

LABOV, W. (1984): “Intensity". En D. Schriffrin (ed.): Meaning, form, and use in context: Linguistic applications. Washington, DC, Georgetown University Press, págs. 43-70.

LABOV, W.- J. WALETZKY (1967): "Narrative analysis". En J. Helm (ed.): Essays on the verbal and visual arts, Seattle, WA, University of Washington Press, págs. 1-24.

LAusBerg, H. (1993): Elementos de Retórica Literaria, Madrid, Gredos.

LEECH, G. (1983): Principles of pragmatics, Londres, Longman. 
LEMKE, J. L. (1992): "Interpersonal meaning in discourse: Value orientations". En M.Davies- L.Ravelli (eds.): Selected papers in Systemic Linguistics, Londres, Pinter, págs. 82-104.

LEMKE, J. L. (1998): "Resources for attitudinal meaning: Evaluative orientations in text semantics", Functions of Language 5 (1), págs. 33-56.

Lo CASCIO, V. (1998, 1991): Gramática de la argumentación, Madrid, Alianza.

LOCHER, M.-R. WATTS (2005): "Politeness theory and relational work", Journal of Politeness Research 1 (1), págs. 9-33.

LÓPez Eire, A.-J. De SANTIAgo Guervós (2000): Retórica y comunicación política, Madrid, Cátedra.

LUTZ, C.A. (1990): "Engendered emotion: Gender, power, and the rhetoric of emotional control in American discourse”. En C.A. Lutz - L. Abu-Lughod, eds., Language and the politics of emotion, Cambridge, Cambridge University Press, págs. 69-91.

MARTIN, J. R. (1995): "Interpersonal meaning, persuasion, and public discourse: Packing semiotic punch”, Australian Journal of Linguistics 15, págs. 33-67.

Martin, J. R. (2000): "Beyond exchange: Appraisal systems in English". En S.Hunston-G.Thompson (eds), págs. 142-175.

Martin, J. R. (2003): “Introduction. Negotiating heteroglossia: Social perspectives on evaluation", Text 23 (2), págs. 1-11.

Martin, J. R. (2004): "Mourning: How we get aligned", Discourse and Society 15 (23), págs. 321-344.

Martin, J. R. - D. Rose (2003): Working with Discourse: Meaning Beyond the Clause, Londres, Continuum.

Martin, J. R.- P. White (2005): The language of evaluation: Appraisal in English, Hampshire y Nueva York, Palgrave Macmillan.

MARTín Rojo, L. (2000): “Enfrentamiento y consenso en los debates parlamentarios sobre la política de inmigración en España”, Oralia, 3, págs.113-148.

MARTín Rojo, L.- T. A. VAN DiJK (1997): “There was a problem, and it was solved!" Legitimating the Expulsion of 'Illegal' Immigrants in Spanish Parliamentary Discourse", Discourse \& Society, 8(4), págs. 523-567.

MARTIN, R. (1980): “Quelques aspects du 'modalisateur””, TRaLiLI, 18, 1, págs. 65-77. 
Matthiessen, C. M. (1995): Lexicogrammatical Cartography: English Systems, Tokyo, International Language Sciences Publishers.

Miche, E. (1998): Secuencias discursivas del desacuerdo. Aplicación del modelo ginebrino al análisis del debate parlamentario del artículo $2^{\circ}$ de la Constitución Española de 1978, Santiago de Compostela, Universidade de Santiago.

NiEMEIER, S.-R. DiRven (eds., 1997): The Language of Emotions. Conceptualization. expression, and theoretical foundation, Ámsterdam/ Filadelfia, John Benjamins.

NúÑEz CABezas, E.-S. Guerrero Salazar (2002): El lenguaje político español, Madrid, Cátedra.

Ochs, E.-B. SchiEfFELIN (1989): "Language has a heart". En E. Ochs ( ed.): The pragmatics of affect. A special issue of Text, Berlín/Nueva York, Mouton de Gruyter, págs. 7-25.

OCHS, E. (1986): "From feelings to grammar: A Samoan case study". En B. Schieffelin - E. Ochs (eds.): Language socialization across cultures, Cambridge, Cambridge University Press, págs. 251-272.

PAINTER, C. (2003): "Developing attitude: An ontogenetic perspective on Appraisal", Text, 23 (2), págs. 183-209.

PALMER, F.R. (1986): Mood and modality, Cambridge: Cambridge U.P.

Perelman, C.- L.Olbrechts-Tyteca (1989): Tratado de la argumentación. Madrid, Gredos.

Pérez de Ayala, S. (1996): Question Time: Cortesía lingüistica en la Cámara de los Comunes, Tesis Doctoral no publicada, Universidad Complutense de Madrid.

PÉREZ DE AYAlA, S. (2001): "FTAs and Erskine May: Conflicting Needs? Politeness in

Question Time”, Journal of Pragmatics, 33, págs. 143-169.

PlacenCIA, M.E. (2007): "El estudio de la cortesía en español: presente y futuro",

L.Cortés et al (eds): Discurso y Oralidad, Madrid, Arco Libros, págs. 113-136.

Placencia, M.E.-D.Bravo (eds. 2002): Actos de habla en español, Munich, Lincom.

Plantin, C. (1998, 1996): La Argumentación, Barcelona, Ariel.

RocCI, A. (2009): “Modalities as Indicators in Argumentative Reconstruction”. En Van Eemeren, F.H.- B. Garssen (eds), 207-228.

SCHIFFrIN, D. (1987): Discourse markers, Cambridge, Cambridge University Press.

SEARle, J.R. (1969): Speech acts. Cambridge, Cambridge University Press. 
SPENCER OATEY, H. (2005): “( $\mathrm{Im})$ politeness, face and perceptions of rapport: unpackaging their bases and interrelationships", Journal of Politeness Research, 1, págs. 95-119.

SPENCER OATEY, H. (ed., 2000): Culturally speaking: managing rapport through talk across cultures. Londres, Continuum.

Stein, D. -S. Wright (eds., 1995): Subjectivity and subjectivisation, Cambridge, Cambridge U.P.

TANNEN, D. (1984): Conversational style: Analyzing talk among friends. Norwood: N.J. Ablex.

Toulmin, S. E. (1958): The Uses of Argument, Cambridge, Cambridge University Press.

Trognon, A.- J. Larrue (eds. 1994): Pragmatique du discours politique, París, Armand Colin.

VAN DiJK, T.A. (2000a): Ideology and discourse. (ed. española en Ariel, 2003) http://www.discourses.org/UnpublishedArticles/Ideology\%20and\%20discourse.p df

VAN DiJK, T. A. (2000b): "Parliamentary Discourse". En R. Wodak y T. Van Dijk (eds): Racism at the Top. Parliamentary Discourses on Ethnic Issues in Six European States, Klagenfurt, Austria, Drava Verlag, págs. 45-78.

VAN DiJK, T. A. (2005): "War rhetoric of a little ally. Political implicatures and Aznar's legitimatization of the war in Iraq", Journal of Language and Politics, 4 (1), págs. $65-91$.

VAN DiJK, T. A. (2007): “La contextualización del discurso parlamentario: Aznar, Iraq y la pragmática del mentir". En L.Cortés et al.: Discurso y oralidad, I, Anejos Oralia 3/1, Madrid, Arco Libros, págs. 137-163.

VAN EEMEREN, F. H.- GROOTENDORST, R. (1992): Argumentation, communication, and fallacies: a pragma-dialectical perspective, Hillsdale, NJ, L. Erlbaum.

Van Eemeren, F. H., \& Grootendorst, R. (2004): A Systematic Theory of Argumentation: The Pragma-Dialectical Approach. Cambridge, Cambridge University Press.

VAn Eemeren, F. H. ET AL. (eds., 2007): Argumentative Indicators in Discourse: A Pragma-Dialectical Study. Dordrecht, Springer. 
VAN Eemeren, F.H.- B. GARssen (eds., 2009): Pondering on problems of Argumentation, Dordrecht, Springer.

VAn Eemeren F.H.- G. Garssen-B. Meuffels (2009): Fallacies and judgements of reasonableness, Dordrecht, Springer.

VOLEK, B. (1987): Emotive signs in language and semantic functioning of derived nouns in Russian, Ámsterdam/ Filadelfia, Benjamins.

Walton, D. N. (1992): The Place of Emotion in Argument. University Park, PA, Penn State University Press.

Walton, D. N. (1998): Ad hominem Arguments, Tuscaloosa, University of Alabama Press.

Watts, R. J. (2003): Politeness, Cambridge, Cambridge University Press.

White, P. R. (2000): "Dialogue and inter-subjectivity: Reinterpreting the semantics of modality and hedging". En M. Coulthard et al. (eds.) Dialogue analysis VII: Working with dialogue. Selected papers from the 7th international association of dialogue analysis conference, Birmingham/ Tubinga, Niemeyer, págs. 67-80.

White, P. R. (2002): “Appraisal: The language of evaluation and stance”. En J. Verschueren et al. (eds.): The handbook of pragmatics. Ámsterdam/ Filadelfia: Benjamins, págs. 1-23.

White, P. R. (2003): "Beyond modality and hedging: A dialogic view of the language of intersubjective stance”, Text 23 (2), págs. 259-284.

White, P. R. (2004): "The language of attitude, arguability and interpersonal positioning”, http://www.grammatics.com/appraisal/index.html. [Consulta: 25/04/2012].

Wilson, J. (1990): Politically Speaking: The Pragmatic Analysis of Political Language. Oxford, Basil Blackwell.

Woods, J. - Walton, D. (1989): Fallacies. Selected papers 1972-1982. Dordrecht/ Providence: Foris Publications.

Woods, J.- Irvine, A.- Walton, D. (2004). Argument. Critical Thinking, Logic and the Fallacies, Toronto, Pearson-PrenticeHall.

Wowk, M. T.(1989): “Emotion talk”. En B. Torode, ed.: Text and talk as social practice, Dordrecht, Foris, págs. 51-71. 
ZAVADIL, B. (1968): "Medios expresivos de la categoría de modalidad en español", Ibero-americana Pragensia, Año 11, págs. 57-86.

ZimMERMAN, K. (2003): Constitución de la identidad y anticortesía verbal entre jóvenes masculinos hablantes de español”. En D. Bravo (ed. 2003): Actas del primer coloquio del Programa EDICE, Stockholms Universitet, págs. 47-59.

Recibido: 19 febrero 2012

Aceptado: 23 marzo 2012

Revisado: 5 abril 2012

Publicado: 20 abril 2012

Actualizado: 23 abril 2012 